\title{
The Application of Solution and Laser Ablation Based ICP-MS and Solution Based AES for the Provenance Determination of Selected Food and Drink Produce
}

\author{
R. John Watling*, Garry S. Lee, Cameron J. Scadding, Tamara S. Pilgrim, Rachel L. Green, \\ Alex E. Martin, Christopher D. May and Jenna L. Valentin
}

Centre for Forensic Science, University of Western Australia, M420, 35 Stirling Highway, Crawley, Western Australia, WA 6009, Australia

\begin{abstract}
The provenance identification of selected types of food and drink was undertaken from data obtained using both solution and laser ablation based inductively coupled plasma mass spectrometry (ICP-MS) and solution based inductively coupled plasma atomic emission spectroscopy (ICP-AES) analysis of selected food and drink materials (pork, wine, tea, coffee and olive oil). Quantitative determination of up to 55 elements was undertaken using solution based ICPMS and AES while counts per second data for 49 elements was used for samples analyzed using Laser Ablation Inductively Coupled Plasma Mass Spectrometry (LA-ICP-MS). ICP-AES was used to determine the concentrations of Na, $\mathrm{K}, \mathrm{Ca}, \mathrm{Mg}$ and $\mathrm{Fe}$ where appropriate. A quantitative analytical methodology for LA-ICP-MS analysis of olive oil was also developed and preliminary trials undertaken. Additional information, to establish more detailed geographic resolution in provenance determination, especially for tea and coffee (plantation of origin), was provided by the incorporation of data for light stable isotope distribution patterns $\left({ }^{2} \mathrm{H}(\mathrm{D}),{ }^{13} \mathrm{C}\right.$ and $\left.{ }^{15} \mathrm{~N}\right)$. LA-ICP-MS was used for the direct analysis of olive oil and coffee beans. The use of laser ablation for the analysis of olive oil has the potential to overcome problems associated with both acid dissolution and thermal oxidation of this material, which are the traditional methods of sample dissolution and which either introduce significant contamination or cause the loss of volatile organo-metallic compounds that may be indicative for provenance determination. Results from the overall study indicated that it was possible not only to establish country of origin of the study materials but also in some cases to improve resolution of provenance to state of origin (wine and pork), and even plantation of origin (tea and coffee).
\end{abstract}

Keywords: Food fraud, inter-element relationships, light stable isotopes, isotope ratio mass spectrometry, linear discriminant analysis, trace elements profiling.

\section{INTRODUCTION}

Fraudulent activities such as the intentional counterfeiting, substitution, adulteration or mislabeling of food to gain an economic advantage are major issues facing the food industry. This is especially true in Eastern Europe, Asia and South America where cheap alternatives and labour mean that counterfeiting or substitution of high quality or brand name commodities can be highly profitable. In 2004, a New Zealand investigative team uncovered a sub industry within China set up to manufacture labels, cartons and packaging of well known brands such as Zespri and Sunkist [1]. Premium New Zealand kiwifruits commands up to ten times the price of local produce in the Chinese market. This behaviour is not confined to these regions, as substitution of cheap foreign produce has recently been reported on sale as premium Australian produce in supermarkets in Britain and Singapore [2]. Australia itself is not exempt from fraudulent behaviour. In 2007, a large Australian pork processor, in an attempt to increase profits during the Christmas period, purchased

*Address correspondence to this author at the Centre for Forensic Science, University of Western Australia, M420, 35 Stirling Highway, Crawley, Western Australia, WA 6009, Australia. Tel: +618-6488-4488; Fax: +6186488-7285; E-mail: John.Watling@uwa.edu.au
Danish ham and wrapped it around Australia pig bones, selling it as "ham off the bone" and an Australian product [3].

Food fraud is highly lucrative because, unlike CD's, shoes, handbags or high end items such as Rolex watches, food is cheap, easy to copy and frauds are difficult to detect. Food is also a necessity in life and consumers are largely ambivalent as to its origin as long as it is both available and affordable. There is also a growing demand for "named brand" foods at a cheaper cost. Food fraud is usually either not reported or the food product is consumed before the fraud is realized. Because of this, it is hard to judge exactly the size of the problem. However, a 2008, Organization of Economic Cooperation and Development report on piracy and counterfeiting, estimated that counterfeit foods and beverages represent anywhere from $€ 2.6$ - 13.9 billion in losses per year [4]. The World Customs Institute in 2009 estimated the counterfeit food industry to be worth about $\$ 49$ billion a year.

Since the mid 1980's, there has been an increase in both research and in the development of techniques to enable the food industry to determine the geographical origin of foodstuffs. Initially, agricultural products such as coffee, tea, wine and olive oil provided a focus for application of the newly developing techniques. This was because high quality 
growing and production regions for these products were well established. In 1992, the European Union passed legislation to protect the reputation of regional foods and eliminate the unfair competition and misleading of consumers resulting from non-genuine products. This legislation contained geographical indications such as Protected Designation of Origin (PDO), Protected Geographical Indication (PGI) and Traditional Speciality Guaranteed (TSG) to protect the names of regional foods. As such, many traditional brands and types of foods associated with regions in Europe, for example Champagne, Gorgonzola, Parmigiano-Reggiano and Black Forest (ham), were protected and names associated with them could only be used to describe produce from these areas. As a consequence, research in developing techniques to provenance cheese, wine, honey, milk and other protected products have increased. In the twenty first century, as more sophisticated techniques were developed, more complicated food matrices [5] such as lamb [6], beef [79], pasta and chicken were investigated to varying degrees of success. Kelly et al. [10] provides an excellent review of the range of foodstuffs covered, while Luykx and van Ruth [11] and Peres et al. [12] provide reviews of technology used to achieve provenance. The European Economic Community (EEC) has just finished funding a five year research project, TRACE, aimed at using analytical methods to verify the origin of food products [13].

A relatively new and often unheard of area of forensic provenancing is the determination of the origin of food products. The market for certain produce is often dominated by particular countries or regions whose reputation for the production of high quality produce provides them with the means by which they can demand a higher price for their specific product than the average. This opens the door for the fraudulent labelling of products as a means of taking advantage of the willingness of the consumer to pay the higher price. In the UK, the Food Standards Agency (FSA) estimates the level of food fraud at 10 per cent, equating to around $\$ 7$ billion' [14]. The ease by which society can be crippled as a result of food borne disease and contamination, whether or not as a result of deliberate tampering, makes the food industry vulnerable and increases the importance of food traceability.

\subsection{Basis of the Technology}

The trace element composition of plant materials, and animal products from animals which graze or consume plants as a nutrition source, is known to be affected by the substrate in which the plant is grown [15]. Plants grown in different geographical locations would be expected to exhibit different trace element profiles as a result of growing in the different soils produced, over time, from the weathering of local rocks. While it can be argued that similar precursor rock types do give rise to specific soil types, better suited to the growth of individual species of plants, is unlikely that the trace element geochemistry and precursor-mineralogy of these rock types will be equivalent as each area has been subjected to a wide variety of igneous and metamorphic processes during petrogenesis. Consequently the trace and ultra-trace element composition of soils derived, even from seemingly equivalent parent rocks, will differ often significantly and therefore the uptake regime of trace elements from the soils in specific areas will be area dependent. Trace element profiles of plants have also been shown to be affected by the fertilizer application regimes and other treatment processes [15]. As an example, the trace element composition of the tea would therefore be expected to change according to the growing region and the fertilizer application practices of specific gardens.

\section{EXPERIMENTAL}

\subsection{Sample Dissolution and Analysis for Solution Based ICP-MS and ICP-AES}

Similar dissolution and analysis procedures were used for all sample types investigated in the studies detailed in this paper. However, pork samples were treated differently as these were dissolved without drying. Normally, samples (approx. $1 \mathrm{~g}$ ) were accurately weighed into conical flasks in triplicate. For all samples, with the exception of pork, nitric acid $(20 \mathrm{~mL})$ (Ajax Finechem, NSW, Australia, AnalaR, sub-boiling quartz still redistilled) was added to each sample. The flasks were covered with watch glasses and then placed on hotplates at $140{ }^{\circ} \mathrm{C}$ for eight hours. The temperature was reduced to $90{ }^{\circ} \mathrm{C}$ and samples left overnight. After this period, the watch glasses were removed and the nitric acid evaporated to leave a yellow residue. A further volume of nitric acid $(10 \mathrm{~mL})$ was added and the flasks, covered by watch glasses, were placed, on hotplates at $160{ }^{\circ} \mathrm{C}(2 \mathrm{hrs})$. After this time the watch glasses were removed and the nitric acid evaporated. When dry, 4:1 nitric/perchloric acid mixture (15 mL) (Ajax Finechem, NSW, Australia, AnalR, subboiling quartz still redistilled) was added to each flask. The flasks were again covered by watch glasses and placed, on hotplates at $180{ }^{\circ} \mathrm{C}(3 \mathrm{hrs})$. After this time, the temperature was reduced to $100{ }^{\circ} \mathrm{C}$ and the samples left overnight to react. In the morning, the lids were removed and the nitric/perchloric acid mixture evaporated to dryness leaving a white residue. The sample was cooled to room temperature and then taken into solution with approx $20 \%$ nitric acid $(7.5 \mathrm{~mL})$ and gentle warming. The solution was transferred into pre-weighed and pre-cleaned (by soaking for $48 \mathrm{~h}$ in 10 $\%$ nitric acid, washing with deionised water and air drying upside down) $70 \mathrm{~mL}$ plastic tubs. The flasks were rinsed several times with MilliQ water with the washings being added to the tubs. The solutions were made up to $50 \mathrm{~g}$ using MilliQ water. Certified Reference Materials (CRMs), peach leaves and apple leaves (National Institute of Standards and Technology SRM 1547 and 1515 respectively), were also included as samples during the digest. $0.5 \mathrm{~g}$ of each was weighed out in triplicate. The CRMs underwent the same acid dissolution procedure as the analytical samples. Three acid blanks, which had also been taken through the entire dissolution procedure, were also included. A multi-element standard was run every 10 analyses to allow for drift correction. Correction and normalization was carried out to the CRMs.

The perchloric based dissolution component of the dissolution procedure was not used for the dissolution of pork. Pork meat represents a highly complex matrix consisting of water, protein, intramuscular fat, carbohydrates, amino acids, and trace amounts of inorganic minerals and it was considered unacceptable to dry this material before dissolution for fear of losing organometallic components. A nitric acid/hydrogen peroxide procedure was conse- 
quently developed to digest the protein matrix with the hydrogen peroxide step to destroy any residual fats. Samples of approximately $2 \mathrm{~g}$ wet mass were accurately weighed and placed in $50 \mathrm{~mL}$ polyethylene screw topped tubes, nitric acid (approximately $5 \mathrm{~mL}$ ) (Ajax Finechem, NSW, Australia, AnalR, sub-boiling quartz still redistilled) was added and the mixture left for 4 hours to react at room temperature. After this time $2 \mathrm{~mL}$ of hydrogen peroxide were added to each tube and the tubes were transferred to a water bath, and suspended in water at approximately $90{ }^{\circ} \mathrm{C}$ for a further 12 hours. The mouths of the tubes was loosely closed with the original tube tops to provide limited reflux of volatilized acid. After 12 hours the tops of the tubes were removed and the mixture allowed to evaporate to a volume of approximately $2 \mathrm{~mL}$. After this time the solutions were rinsed out with deionised water into suitable pre-cleaned 15 $\mathrm{mL}$ plastic tubes (cleaning was achieved by soaking for $48 \mathrm{~h}$ in $10 \%$ nitric acid, washing with deionised water and air drying upside down), and made up to $10 \mathrm{~mL}$ prior to ICPMS and ICP-AES analysis.

Prepared solution samples were analyzed using an Agilent $7500 \mathrm{CS}$ inductively coupled plasma mass spectrometer (Agilent Technologies, Tokyo, Japan) and a Thermo Fisher Scientific Inc. iCap 6500 ICP-AES spectrophotometer, (Thermo Fisher Scientific Inc, North Ryde New South Wales, Australia).

\subsection{LA-ICP-MS}

A UP $213 \mathrm{~nm}$ Nd:YAG laser ablation instrument (New Wave Research Co. LTD., Cambridgeshire, England) was used for all analyses. Laser ablation was undertaken in three different ways. For each protocol the laser was operated at $6 \mathrm{~Hz}$ in continuous ablation mode and scanned across the surface of the sample to produce a 'line ablation'. Lines of approximately $500 \mu \mathrm{m}$ were traversed across the various surfaces, a process taking approximately 90 seconds of ablation time. Continuous (Time Resolved Analysis (TRA)) data collection was used to acquire analytical data. In this way, it was retrospectively possible to remove 'spikes' in data due to non-uniform ablation caused by variations in surface topography of the sample. National Institute of Standards and Technology (NIST) 610 and 612 glass standards were used to optimize the sensitivity of the instrument and facilitate correction of instrumental drift. Before the analysis of each sample, data for approximately 30 seconds of 'gas blank' were collected to facilitate background correction. Argon carrier gas was used with the addition of helium as an optional gas to improve sensitivity. The instrumental conditions were optimized daily to allow for high signal with low $\%$ RSD. The instrument was initially tuned to a NIST 612 standard. The tuning was adjusted for the oil analysis using a $2 \mathrm{ppm}$. In standard made from a 1000 ppm Conostan $^{\mathbb{B}}$ organo-metallic standard (Conostan Division, Conoco Specialty Products Inc., Oklahoma). The solenoids that control the bypass and flow of gas through the laser cell were bypassed and a manual tap system set up to prevent contamination of the solenoid itself by the oil, when olive oil was being analyzed. Oil based organo-metallic calibration standards were produced from a custom made Conostan $^{\circledR}$ organometallic standard containing $\mathrm{Li}, \mathrm{Be}, \mathrm{Mg}$, $\mathrm{Al}, \mathrm{Ti}, \mathrm{V}, \mathrm{Cr}, \mathrm{Mn}, \mathrm{Fe}, \mathrm{Co}, \mathrm{Ni}, \mathrm{Cu}, \mathrm{Zn}, \mathrm{Sr}, \mathrm{Mo}, \mathrm{Ag}, \mathrm{Cd}, \mathrm{In}$, $\mathrm{Sn}, \mathrm{Sb}, \mathrm{Ba}$ and $\mathrm{Pb}$.

\subsection{EA-IRMS}

Analysis was performed using a Micromass IsoPrime isotope ratio mass spectrometer interfaced to a EuroVector 149 EuroEA3000 elemental analyzer. Prior to analyzing the samples for bulk isotope values, the dried material was ground to a fine powder $(<500 \mu \mathrm{m})$ using an agate mortar and pestle.

For ${ }^{13} \mathrm{C}$ analysis, $150-200 \mu \mathrm{g}$ of powder were weighed into a small tin capsule. This was then folded and compressed to contain the sample and minimize any air present. The prepared samples were introduced into the elemental analyzer using an auto sampler. The stable carbon isotopic composition was recorded in the delta notation relative to the Vienna Pee Dee Belemnite (VPDB) standard. $\mathrm{CO}_{2}$ of known ${ }^{13} \mathrm{C}$ content was introduced as a pulse of reference gas. Each sample is analyzed a minimum of three times and the average and standard deviations calculated (Values ranged between -29.1-23.2\%o $\pm 0.23(\mathrm{SE})$ ). An inhouse sucrose standard and a beet sugar standard (IsoAnalytical IA-R005) of known ${ }^{13} \mathrm{C}$ values (-10.5 and $26.03 \%$, respectively) were used for calibration purposes. Samples were analyzed over a period of 18 months, with replicate samples analyzed throughout the entire period to ensure reproducibility of results.

For ${ }^{15} \mathrm{~N}$ analysis, 2-4 mg of samples were weighed and analyzed in a similar manner to the samples used for carbon isotope analysis. Due to the increased amount of sample, the dilutor was switched on just prior to the elution of the $\mathrm{CO}_{2}$ peak and switched off immediately after to prevent the detector from being overloaded with $\mathrm{CO}_{2}$. The ${ }^{15} \mathrm{~N}$ composition is reported relative to a reference gas pulse of known ${ }^{15} \mathrm{~N}$ composition. The isotopic compositions are recorded in delta notation relative to an air standard. Each sample is analyzed a minimum of three times and the average and standard deviations calculated (values ranged between $0.2 \& 7.1 \% \pm 0.22(\mathrm{SE})$ ). A wheat flour standard (IsoAnalytical IA-R001) and Urea standard (EuroVector E11003) of known ${ }^{15} \mathrm{~N}$ values $(2.55$ and $-0.5 \%$, respectively) were used for calibration purposes. Samples were analyzed over a period of 18 months, with replicate samples analyzed throughout the entire period to ensure reproducibility of results.

For ${ }^{2} \mathrm{H}(\mathrm{D})$ analysis, sample powders weighing between 550 and $650 \mu \mathrm{g}$ were weighed into a small silver capsule. This was folded and compressed to contain the sample and to remove any air. The prepared sample was introduced into the elemental analyzer using an auto sampler. Hydrogen gas of known $\delta \mathrm{D}$ was inserted as pulses of reference gas. The gas is passed into the irMS and the isotope composition calculated using the delta notation relative to the Vienna Standard Mean Ocean Water (VSMOW) standard. Each sample is analyzed a minimum of three times and the average and standard deviations calculated (Values ranged between -93.4 $\&-11.5 \% \pm 0.89(\mathrm{SE})$ ). Polyethylene (IAEA-CH7) and Mineral Oil (IA-R002) standards (D $=-100 \%$ and $-111 \%$, respectively) were used for calibration purposes.

Samples were analyzed over a period of 18 months, with replicate samples analyzed throughout the entire period to ensure reproducibility of results and that the results were not being affected by exchangeable hydrogen. 


\subsection{Software and Statistical Techniques}

Linear discriminant analysis (LDA) was undertaken throughout this study to establish grouping of samples. LDA generates a set of discriminant functions based on linear combinations of the predictor variables that provide the best discrimination between the groups. The functions are generated from a sample of cases for which group membership is known; the functions can then be applied to new cases that have measurements for the predictor variables but have unknown group membership, thus allowing the group membership to be predicted. LDA was carried out using the stepwise method in which the model is built step by step. Variables are evaluated at each step; the variable that gives the best discrimination between groups is included in the analysis.

LDA provides a range of statistics associated with the degree to which a sample can be correctly classified. One classification test that can be performed on the data is crossvalidation. In this test, each of the known data points is entered into the database as an unknown and the classification for that sample determined according to the functions derived from the remainder of the known variables. The percentage obtained at the end of this ( $\%$ cross validated cases correctly classified) provides an indication of the number of samples that will be correctly classified in a given dataset.

\section{RESULTS AND DISCUSSION}

\subsection{Wine}

Internationally, Australian wines command a high premium because viticultural practices within the country are of an exceptionally high standard and consequently the product has developed an international reputation for consistent quality. However, recently, cases of fraudulent labelling of Australian wine, both within the country and internationally, have been confirmed, and with the Australian wine export market alone valued at approximately AU \$3 billion per annum, this type of activity, if unchecked, threatens to cause significant problems to the industry directly and to Australia's reputation as a quality wine producing nation.

The research undertaken has demonstrated that ICP-MS and ICP-AES can be used to determine the minor and trace elements present in the wine products. The wine products were diluted and then analyzed directly using ICP-MS and ICP-AES. Analyte concentrations were determined by comparison with alcohol spiked multi-element calibration standards. To facilitate the characterization of wines, based on their geographical origin, it has been necessary to construct a database of known trace element profiles for each wine variety of each wine growing region. This database currently contains over 1800 samples and has been developed by analysis of samples provided by research wineries and the Australian Wine and Brandy Corporation. The trace element profile determined for cabernet sauvignon sourced from Margaret River and Yarra Valley, Victoria, are illustrated in Fig. (1).

The results illustrated in Fig. (1) demonstrate that the determined trace element profiles can be used to distinguish wine from different regions. The Yarra Valley profile can be visually discriminated from those profiles determined for wines from the Margaret River area of Western Australia. The visual comparison of trace element profile is only practical for a small number of samples, as the plots, equivalent to those in Fig. (1), become significantly more complex and differences become difficult to identify when dealing with large numbers of samples. It is therefore necessary to reduce the data into a format in which visual and statistical grouping of samples is possible. To do this Linear Discriminant Analysis (LDA) techniques are used. LDA is a statistical method which can reduce elemental data to a single point on a two dimensional chart. LDA attempts to separate samples according to user-defined groups (in this case region of origin). If samples do separate into these groups on the chart according to their region of origin, then there must be generic differences in the chemical fingerprints of wines from these regions. However, if the groups do not separate, it can be concluded that the trace element profiles of the wines from the regions are comparable.

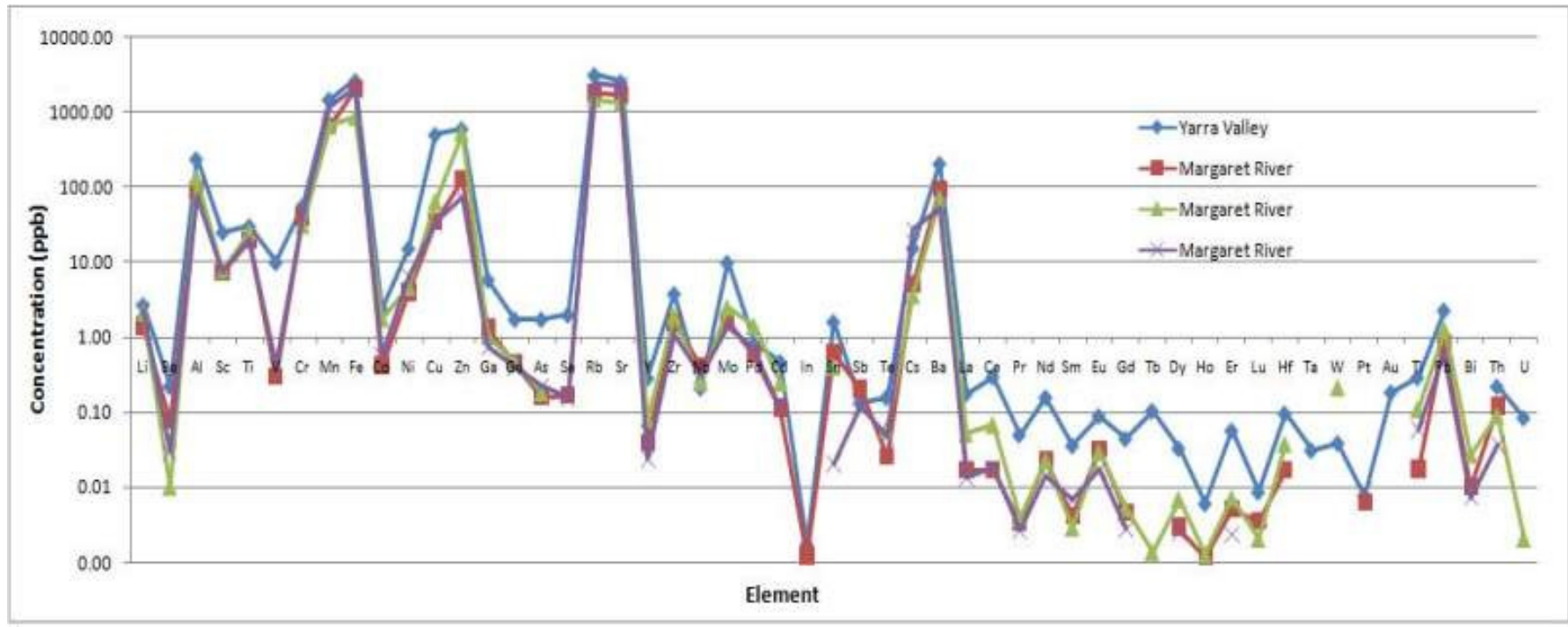

Fig. (1). Trace element profile determined for three cabernet sauvignon samples from Margaret River and one sample from the Yarra Valley. 
The results illustrated in Fig. (2) demonstrate that Shiraz samples sourced from six different growing regions can be visually discriminated. This discrimination is based on the trace elemental data determined for each wine sample. Similar results have been achieved for all different grape varieties. After the successful optimization of the analytical methodology, the concentrations of 55 elements have been determined in approximately 1850 samples of Australian and international wines using solution-based ICP-MS. These samples are being continuously added to and act as a reference data base for the product. Interpretation of the data has demonstrated that while the trace element composition of wine is largely independent of vintage and grape variety, it does have a strong dependence on the region/country in which the wine was produced. The application of multivariate statistics has facilitated discrimination of data for wine samples according to their country/region of origin. In addition to in-house blind trials, the analytical and interpretational protocols developed have been successfully trialed in two separate, internationally significant, cases of potential wine fraud, the results for one of these investigations is still current and cannot therefore be discussed in detail and consequently the actual name of the vineyard involved cannot be mentioned.
A suspect bottle of a 2005 Shiraz was received from the Australian Wine and Brandy Corporation for analysis. This bottle of wine was a return from China and the origin of this bottle had been called into question. No additional reference samples were received, as this wine was to be compared to the existing database for the purpose of establishing whether this wine was Australian, and if so, the region it was likely to originate from. Ten separate samples of the equivalent Shiraz (of known provenance) were analyzed in order to ensure the accuracy of the data obtained. When LDA was applied to this case, the user-defined groups were based upon the geographical origin of the wine samples. If the data could be separated according to these groupings, then it could be concluded there are generic differences between the trace element concentrations of the wines comprising each of these groups.

The first comparison undertaken was between the ten analyses performed on the suspect bottle and an appropriate subset of the reference database including the ten samples of the Shiraz of known provenance. As the database contained data associated with both red and white wines and samples obtained directly out of barrels during the winemaking process as well as from bottled wine, it was necessary to remove the samples not relevant to the case. Therefore, the

\section{Canonical Discriminant Functions}

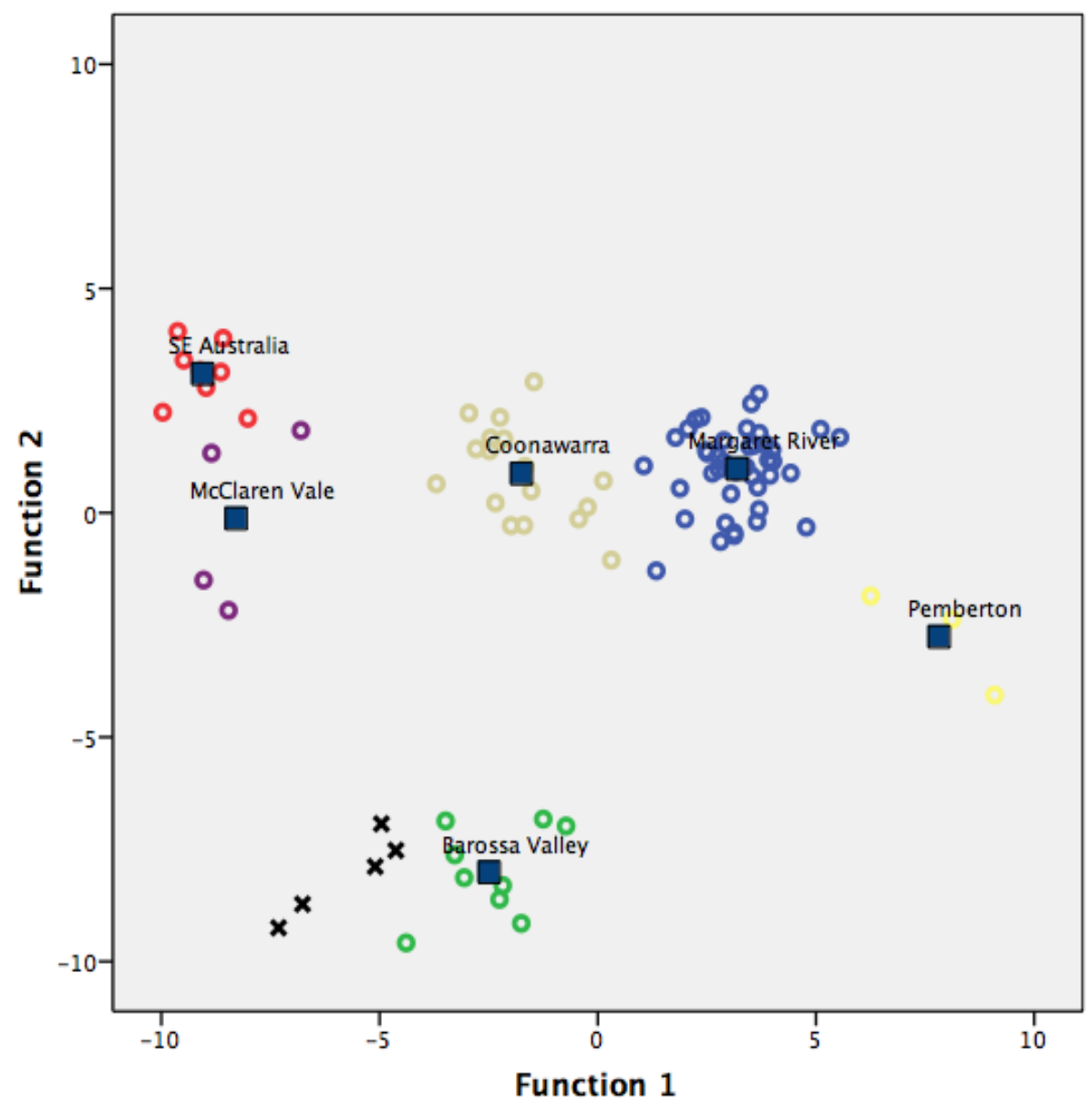

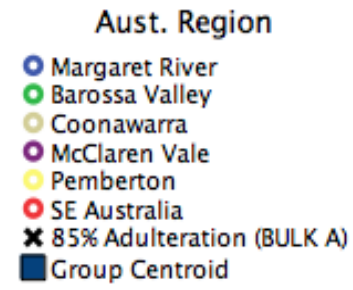

Fig. (2). Plot of first 2 discriminant scores determined for trace element profiles determined for Shiraz samples sourced from six regions. 
only data utilized for LDA was that associated with bottled samples of red wines from Australia and Argentina, leaving a total of 455 samples for comparison. Argentinean wines were included because for LDA to generate a two dimensional plot, three groupings must be defined. It should also be noted that while the wine in question was labelled as being a Shiraz, red wines produced from other grape varieties were still included for comparison because if the origin of the wine proved to be different to what was stated on the label, then it would be possible that the same would also apply to the grape variety.

The discriminant plot resulting from LDA performed on data associated with Australian and Argentinean red wine samples and the suspect wine sample is detailed in Fig. (3). LDA was able to generate a model that facilitated separation between the Australian wines, Argentinean wines and the wine in question (labelled as "Case") (Fig. 3). This is strong evidence that the elemental composition of the wine in question is significantly different to the 441 samples of Australian wine and 14 samples of Argentinean wine. If the elemental composition of the wine in question was consistent with Australian wines, then the "Case" group would have overlapped with the Australian group.

To further investigate the differences in trace element concentrations between the wine in question and Australian wines, LDA was again performed, this time using only Australian reference samples. However, instead of treating the Australian samples as one group, the reference samples were grouped according to their region of origin. For statistical purposes, only wine regions that were represented in the database by a minimum of five samples were included for comparison. The discriminant plot resulting from this analysis is detailed in Fig. (4). The ability to separate data associated with the suspect bottle of wine from data associated with seventeen different wine regions in Australia further suggests that the elemental composition of the suspect bottle of wine is not consistent with any Australian wine region.

As a result of the analysis and subsequent interpretation of the data associated with the bottle of 2005 Shiraz, it was demonstrated that the wine has a significantly different elemental composition to what is typically observed in Australian wines, especially for wines in the area that it was reported to have come from. Therefore, it is highly unlikely that this wine originated from Australia. Although, most premium wine growing countries have sophisticated product traceability and supply chain management systems in place the development of this new technology underpin the integrity of the wine label providing consumers with confidence and producers with ability to manage their export market access risks.

\subsection{Pork}

In recent years, the pork industry both domestic and international has suffered a number of food related incidents and substitution scandals which have highlighted the need for a robust traceability system that can verify the country of origin of pork meat or trace pork meat back to its farm of origin. The Irish pork dioxin scare of 2008 year highlighted the shortcomings of the British labelling and traceability

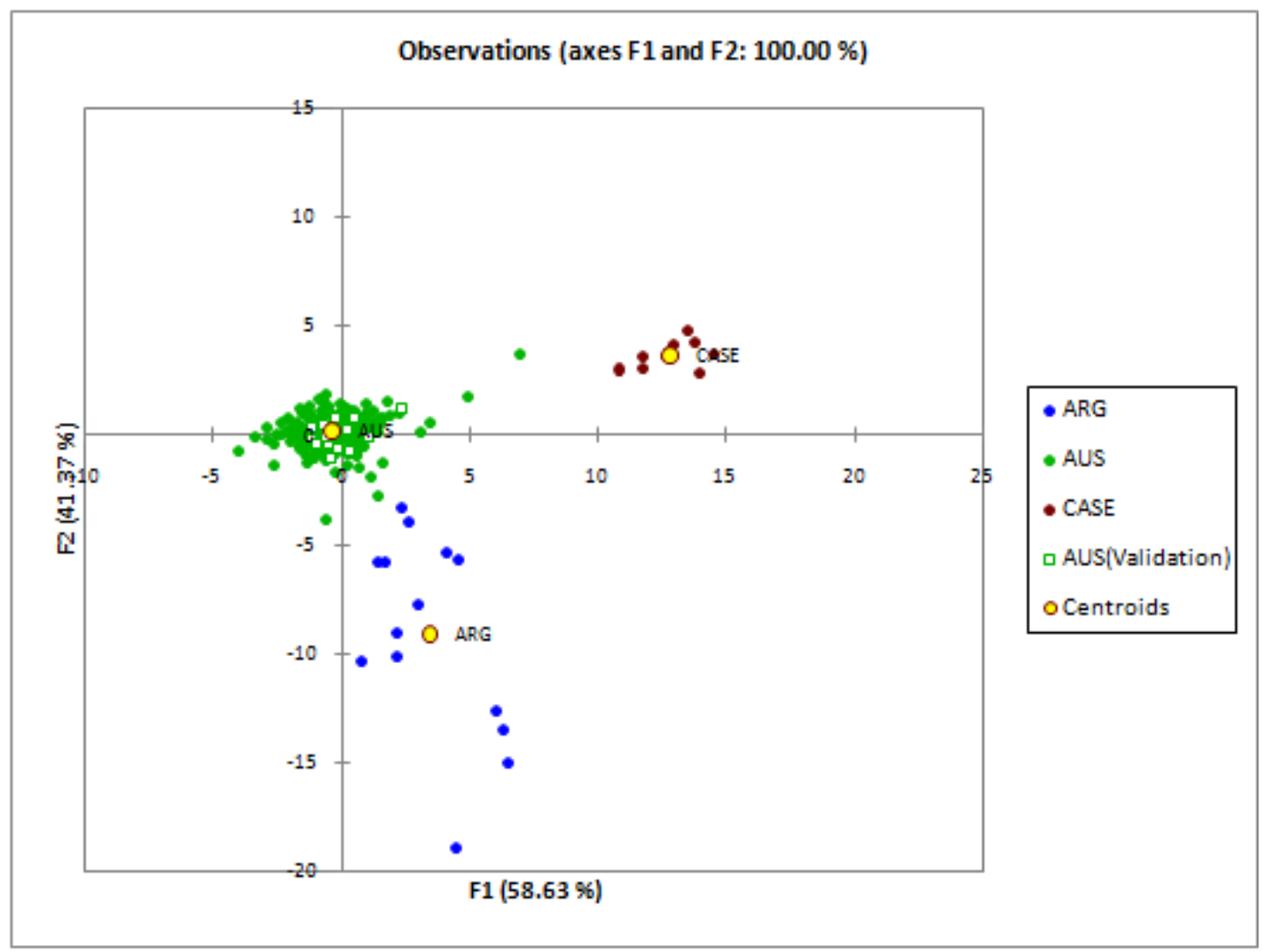

Fig. (3). Discriminant plot generated using forward stepwise LDA detailing separation of data associated with wine samples from Australia, Argentina and the suspect bottle of wine. 


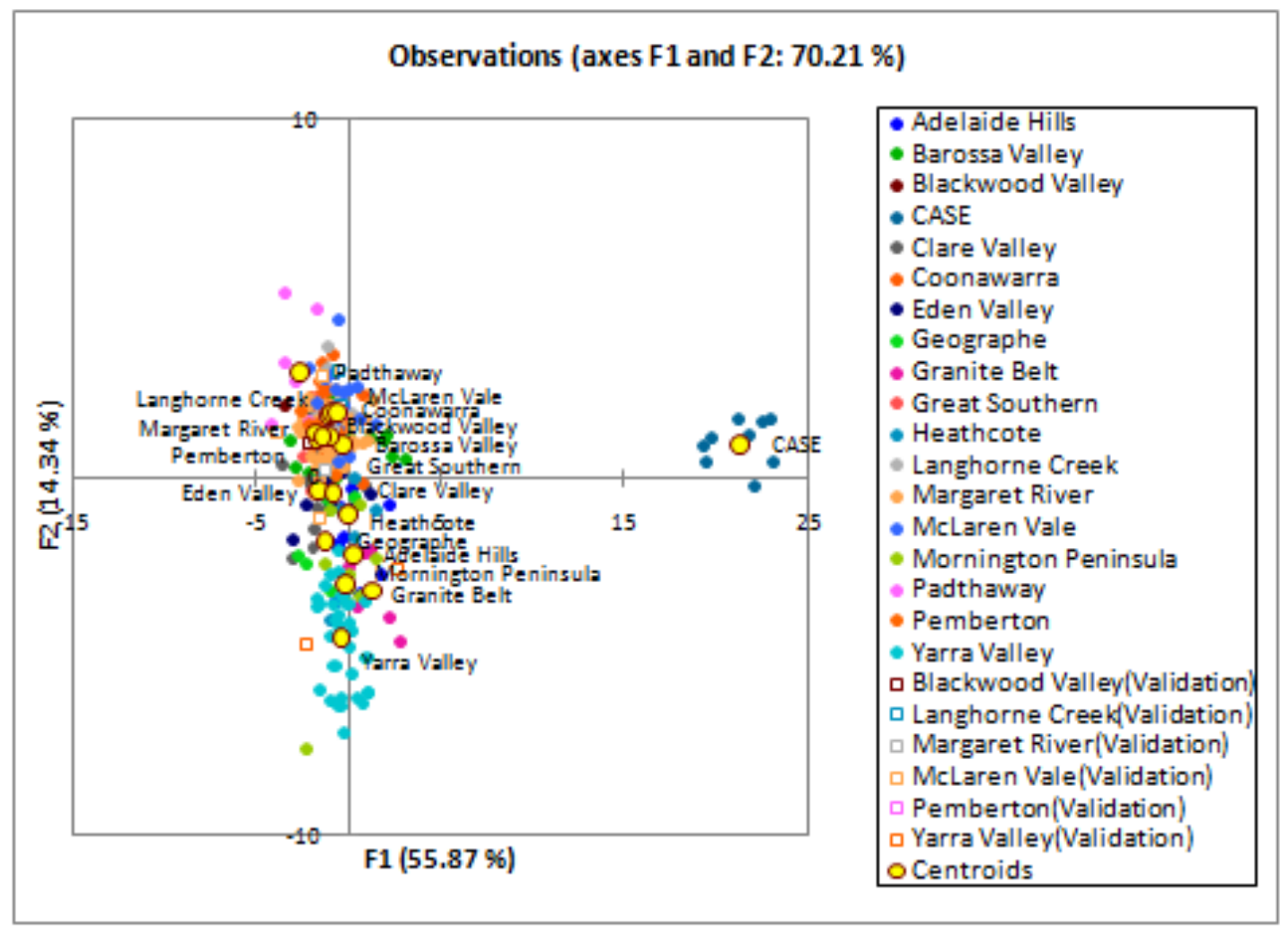

Fig. (4). Discriminant plot generated using forward stepwise LDA detailing separation of data associated with the suspect wine sample from wine samples originating from 17 Australian Wine Regions.

system, with the UK Food Standards Agency admitting that products labelled "Made in Britain" may contain products from other countries. In Australia, a recent evaluation of pigs in sale yards and abattoirs in New South Wales found that current compliance and readability of tattoos would compromise a trace back to the farm of origin in the event of an emergency animal disease outbreak [16]. The aim of the research detailed in this paper was to demonstrate the potential of trace element distribution patterns to trace the geographical origin of pork in Australia and to verify if this approach can be incorporated in the existing paper based traceability system to produce an efficient tool for pork origin characterization.

Fresh pork samples (10-20 g) were collected from the brisket of pig carcasses at six abattoirs in Australia over a period of three months and stored at $-10{ }^{\circ} \mathrm{C}$ until processing. Two sample regimes were used: 1115 samples were collected in the first two months to ensure a good coverage of pig producers. An intense phase followed where a minimum $10 \%$ of the pigs in each farmers "kill lot" were sampled. For "kill lots" containing less than fifty pigs, five carcasses were sampled.

The results of the linear discriminate analysis show that there were highly significant differences between pork from pigs grown in different regions in Australia. Significantly, pork from pigs in Queensland and Western Australia can be easily discriminated by plotting the first two determined discriminant scores (Fig. 5).

Differences between pork from pigs grown in the South Eastern Australian states however were not as pronounced although they could still be separated based on the discriminant analysis. Data detailed in Fig. (6) describes a discriminate plot of the first two functions with the data from Queensland and Western Australia removed. The overlap from the South Australian and Victorian samples is due to farmers sending groups of pigs to processors in both states. While more detailed work is needed, trace elemental profiles show an extremely high potential of providing a powerful tool for the pork industry to determine the state of origin of fresh pork meat.

\subsection{Tea}

The primary aim of this study was to investigate the potential of the methods used for the determination of the growing region of a sample. To that end, the study used a selection of samples whose provenance was accurately known thereby enabling rigorous method validation and confirmation of the potential of the methodologies used for provenance determination. In addition to the study samples, a selection of test samples, purchased from the supermarket, were used to test the classification potential against the database of known samples. In addition to samples being labelled according to their country of origin, the Indian tea samples were also labelled according to their region of origin; Assam, Nilgiri and Darjeeling.

While several studies have already been conducted on tea, these generally have only small sample sets or limited classifications [17, 18]. Trace element concentrations of a limited number of tea samples have been determined using ICP-MS and ICP-AES [19]. Data from this study were used to distinguish between African and Asian teas and separate 


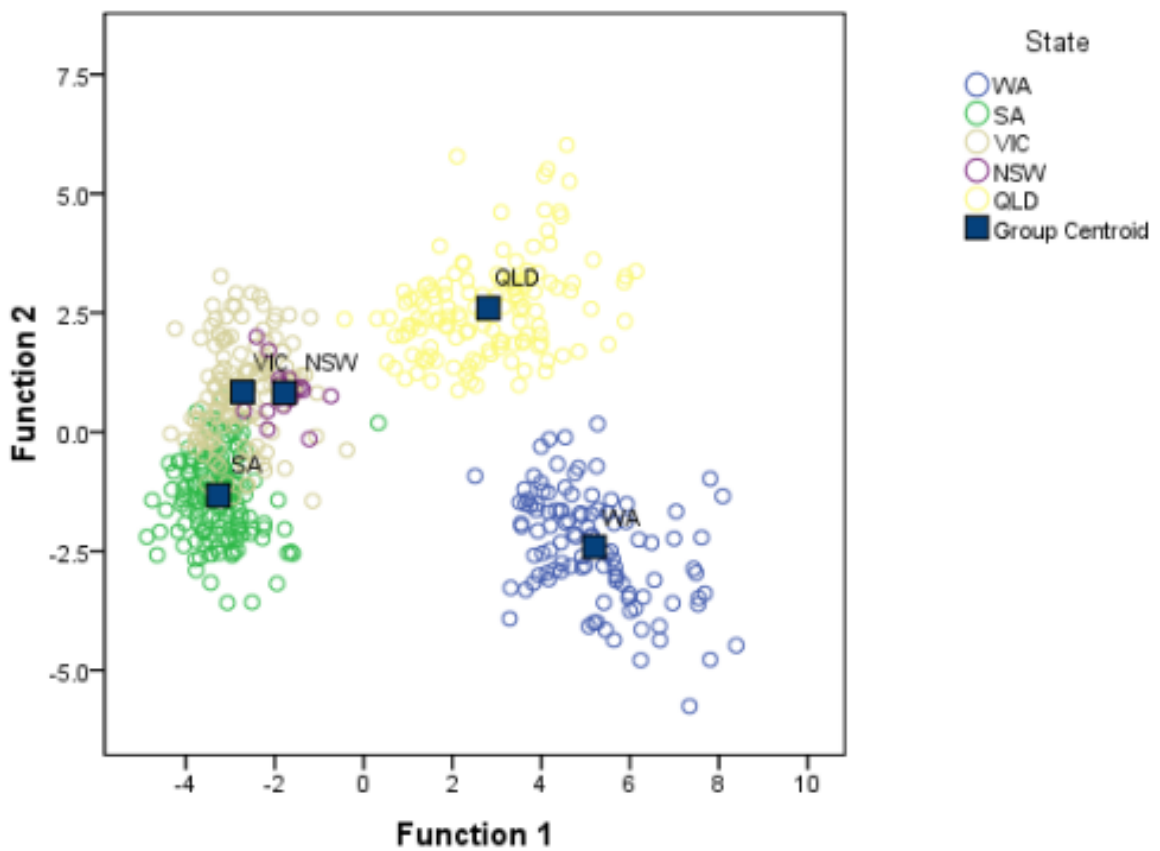

Fig. (5). Scatter plot of first two discriminant functions from stepwise linear discriminant analysis of pork samples according to the state of origin WA - Western Australia; SA - South Australia; VIC - Victoria; NSW - New South Wales; QLD - Queensland.
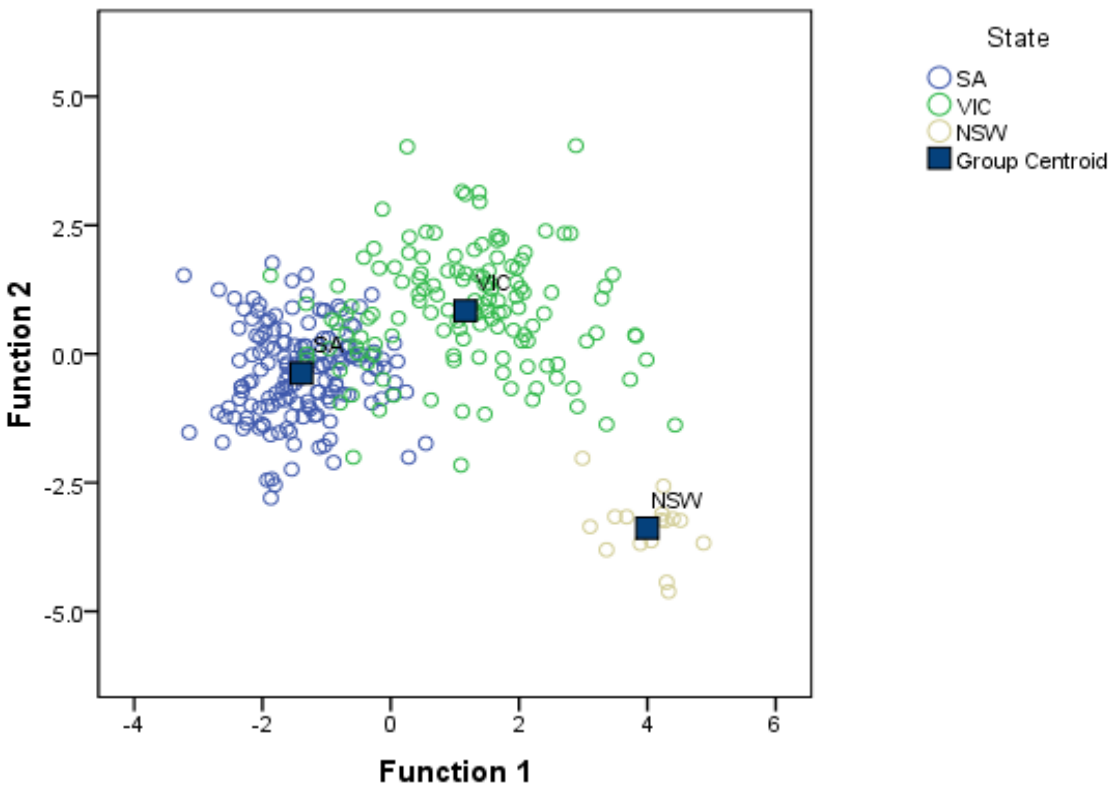

Function 1

Fig. (6). Scatter plot of first 2 discriminant functions from stepwise linear discriminant analysis of pork samples according to the state of origin, Queensland and Western Australian samples removed; SA - South Australia; VIC - Victoria; NSW - New South Wales.

Chinese samples from other Asian samples. However, this was a small study with only 15 samples from 10 different countries and cannot be considered in any way definitive. Similar studies [20-24] have applied multivariate and chemometric techniques to concentration data of the major elements in tea obtained using ICP-AES and ICP-MS to separate and classify Asian, African, Chinese, Indian and Sri Lankan teas. These studies to date have typically relied on discrimination based on either light stable isotopes or trace element data rather than investigating the potential of combining both techniques to provide a more robust and universally applicable provenance determination.
The current study, detailed in this paper, investigates the potential of using a combination of trace element data and stable isotope $(\mathrm{C}, \mathrm{N} \& \mathrm{H})$ for 83 tea samples (Table 1) to establish the growing region. The effects of differences in tea type, harvest date and tea quality on this classification were also studied. Linear discriminant analysis was applied to the data to obtain separation of growing regions and to identify the provenance of samples from different tea growing regions of Asia (China, India, Sri Lanka and Taiwan). The validity of the method for the determination of origin of unknown samples was then tested through the analysis of 20 commercial samples [25]. 
Table 1. Summary of the Tea Samples Used in this Study

\begin{tabular}{|c|c|c|c|c|}
\hline Area & Black & Green & Oolong & Total \\
\hline China & 6 & 6 & 0 & 12 \\
\hline India & 40 & 2 & 1 & 43 \\
\hline Sri Lanka & 19 & 4 & 0 & 23 \\
\hline Taiwan & 1 & 0 & 4 & 5 \\
\hline Commercial & 19 & 1 & 0 & 20 \\
\hline Total & 85 & 13 & 5 & 103 \\
\hline \multicolumn{5}{|l|}{ Indian Tea Regions: } \\
\hline Assam & 6 & 0 & 0 & 6 \\
\hline Darjeeling & 10 & 0 & 1 & 11 \\
\hline Nilgiri & 24 & 2 & 0 & 26 \\
\hline Total & 40 & 2 & 1 & 43 \\
\hline \multicolumn{5}{|l|}{ Nilgiri Tea Gardens: } \\
\hline Chamraj & 2 & 0 & 0 & 2 \\
\hline Glendale & 2 & 0 & 0 & 2 \\
\hline Havukal & 5 & 0 & 0 & 5 \\
\hline Kairbetta & 8 & 0 & 0 & 8 \\
\hline Kondanaad & 1 & 0 & 0 & 1 \\
\hline Korakundah & 3 & 2 & 0 & 5 \\
\hline $\begin{array}{c}\text { Swampy \& } \\
\text { Swampy Plantations }\end{array}$ & 3 & 0 & 0 & 3 \\
\hline Total & 24 & 2 & 0 & 26 \\
\hline
\end{tabular}

All data was log transformed and stepwise discriminant analysis was carried out. Variables were evaluated at each step and the variable giving the best discrimination between groups was included in the analysis. The database for discriminant analysis was formed using the data collected for the known tea samples. Samples were analyzed in triplicate and each analysis was inserted into the database as an individual data point. The commercial tea samples were then inserted into the database as unlabelled cases and the discriminant analysis repeated as a test of the potential of the technique for determining the origin of unknown samples.

As the study uses tea samples whose provenance is accurately known, a rigorous method validation and confirmation of the provenance identification potential of the methodologies could be obtained. Following the verification of the technique, test samples were analyzed and subsequently classified against the database formed with the known samples. Study samples were labelled with their country of origin. In addition, Indian tea samples were subdivided into Assam, Darjeeling and Nilgiri, to allow a secondary classification following the initial country classification. These areas have distinct reputations which are carefully protected and represent the three areas of Indian tea production which this paper is primarily concerned with uniquely identifying. The scatter plot of the first 2 discriminant functions from the analysis of the known tea samples (Fig. 7a) confirms the capability for separation of samples into their growing region. While tea samples from Taiwan and China appear to be inseparable, inclusion of the third discriminant function (Fig. 7b) presents a clear separation of the two regions. Using these three discriminant functions 97.6 per cent of the samples was correctly classified. The variables used to achieve this classification were ${ }^{2} \mathrm{H}$ (D), ${ }^{13} \mathrm{C},{ }^{49} \mathrm{Ti},{ }^{53} \mathrm{Cr},{ }^{59} \mathrm{Co},{ }^{60} \mathrm{Ni},{ }^{65} \mathrm{Cu},{ }^{71} \mathrm{Ga},{ }^{85} \mathrm{Rb}$, ${ }^{88} \mathrm{Sr},{ }^{89} \mathrm{Y},{ }^{93} \mathrm{Nb},{ }^{111} \mathrm{Cd},{ }^{133} \mathrm{Cs},{ }^{138} \mathrm{Ba},{ }^{139} \mathrm{La},{ }^{140} \mathrm{Ce},{ }^{141} \mathrm{Pr},{ }^{153} \mathrm{Eu}$, ${ }^{203} \mathrm{Tl},{ }^{208} \mathrm{~Pb}$ and ${ }^{209} \mathrm{Bi}$.

Following separation of the samples into their country region, it was investigated whether it was possible to separate the Indian tea samples into their individual growing regions. This was of particular interest due to the unique reputation of each of these regions. The discriminant
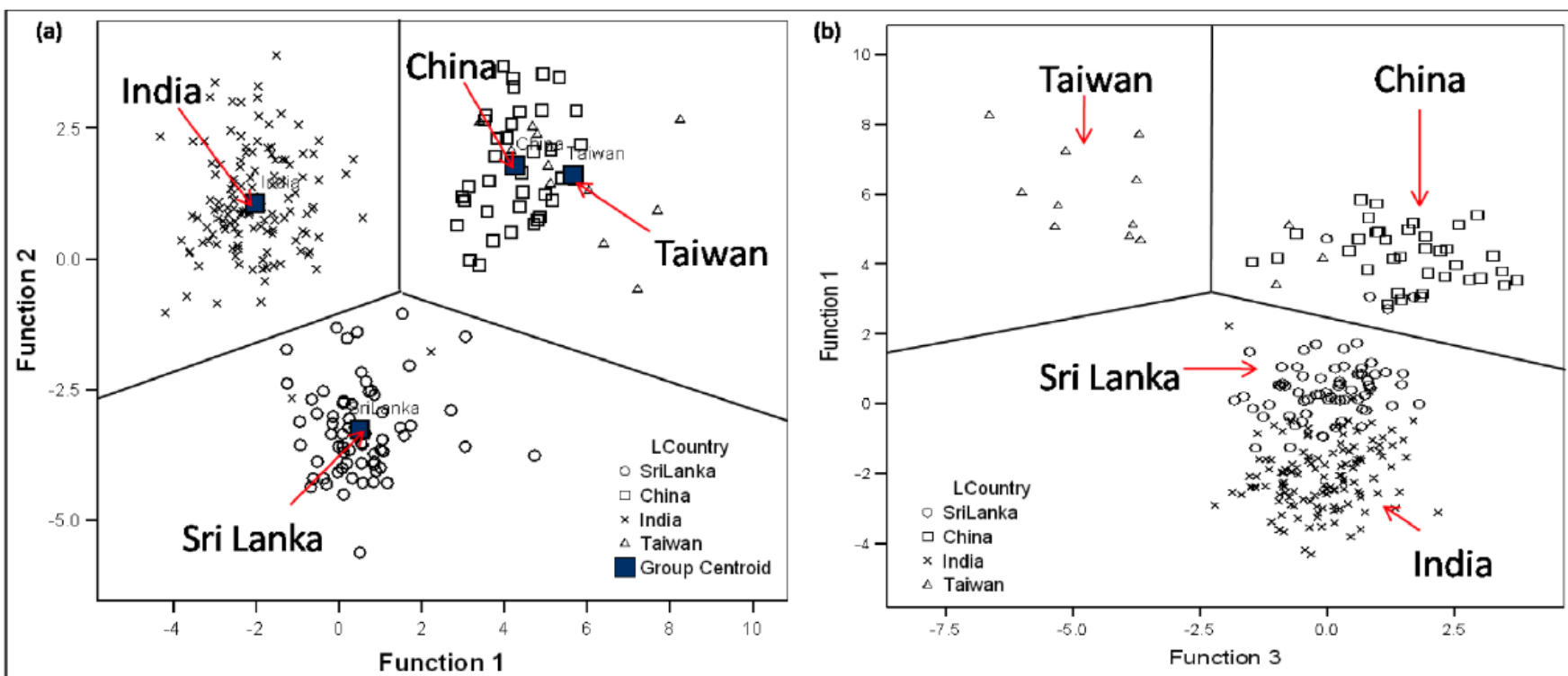

Fig. (7). (a) Scatter plot of the first 2 discriminant functions showing separation between Asian tea growing countries. (b) Scatter plot of discriminant functions 1 and 3 showing separation between China and Taiwan tea samples. 

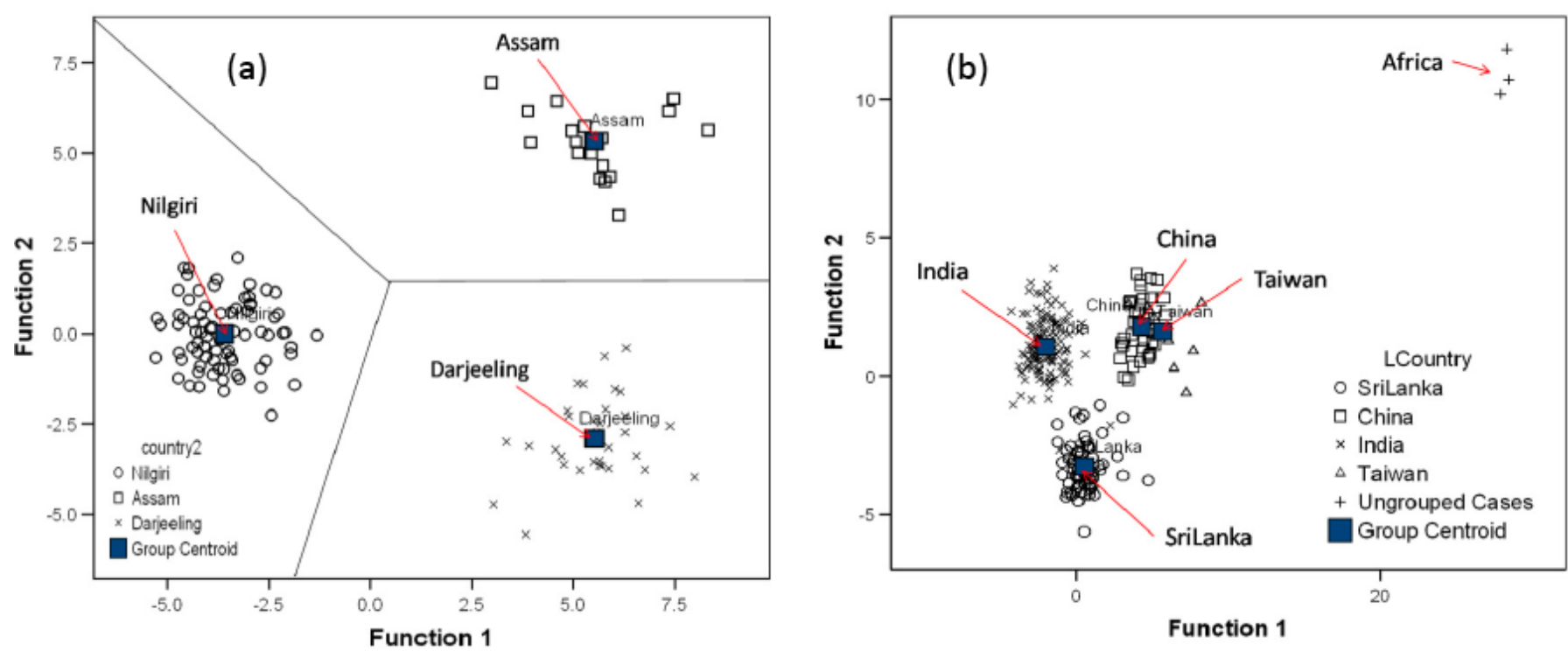

Fig. (8). (a) Scatter plot of the first two discriminant functions showing separation of Indian teas according to growing region: (b) Discriminant plot indicating the grouping of African tea samples (ungrouped cases) compared to the Asian the data base.

analysis was repeated using a separate database consisting of the Indian samples, with classification according to region (Fig. 8a). The main elements contributing to this separation were $\mathrm{Rb}, \mathrm{Cs}, \mathrm{Ga}, \delta \mathrm{D}, \mathrm{Sm}, \mathrm{La}, \delta^{15} \mathrm{~N}, \delta^{13} \mathrm{C}, \mathrm{Y}, \mathrm{Eu}, \mathrm{Er}$ and $\mathrm{Nd}$. For the method to be valid, it is important that when a sample from outside the database area is tested that it will not be incorrectly classified as coming from one of the test regions. To assess this, samples from other regions (including Africa and Australia) were inserted into the discriminant analysis as ungrouped cases. The discriminant analysis was run and the outcome assessed. The results, following entering an African sample (labelled 'Ungrouped Cases') into the database, are presented in Fig. (8b). It can be seen that this sample forms a group completely separate from the Asian tea samples within the database, thus ensuring that misclassification would not occur.

To test the validity of the method, a blind trial was conducted using 20 commercial tea samples. These samples were prepared and analyzed and the data treated in the same manner as the database samples. The sample data was subsequently entered into the database as an ungrouped case and the discriminant analysis conducted to determine the likely growing region of the test samples. Following this the established origin was compared to the label. The majority of the samples could be matched with the listed growing region, while others were classified into an area different to that specified on the label (Fig. 9a, b).
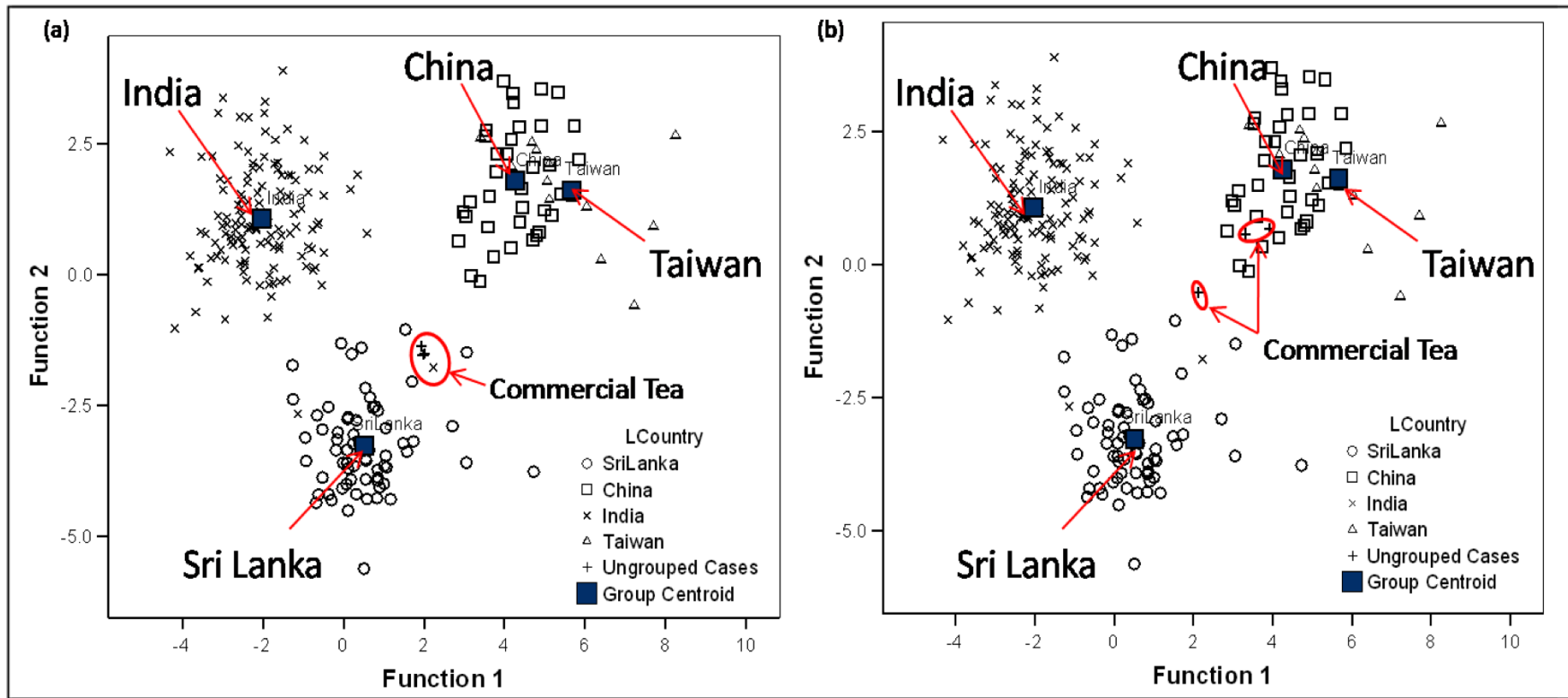

Fig. (9). (a) Example of classification that agreed with sample label. Discriminant plot indicating the grouping of commercial sample 3 (labelled Sri Lanka) compared with the Asian tea database. (b) Example of classification that disagreed with sample label. Discriminant plot indicating the grouping of commercial sample 5 (labelled India) compared with the Asian tea database. 
The data for a sample (labelled Ungrouped Cases) purchased as coming from Sri Lanka is compared with the study data base in Fig. (10a). This sample gave a $100 \%$ match to the Sri Lankan tea samples and can be seen in the discriminant plot grouping with the Sri Lankan tea samples. The data for a sample that did not classify with the other samples came from the same region as the claimed origin of the commercial sample, are detailed in Fig. (10b). This sample was purchased as an Indian tea. When classified using discriminant analysis the sample groups with the Chinese and Sri Lankan samples, with no match to the Indian samples. Commercial Tea 15, labelled Darjeeling, was inserted into the data set. Discriminant analysis grouped this sample with the Indian samples (Fig. 11a). As a further test, this sample was then inserted into the database of Indian teas to determine whether it would be possible to allocate it to a particular growing region within India. Discriminant analysis grouped this sample strongly $(100 \%)$ with the Darjeeling group (Fig. 11b). The analysis was repeated for each of the commercial tea samples. The established origin was then compared to the origin that was provided. The results are summarized in Table $\mathbf{2}$.

The tightness of the grouping of the samples gives an indication of the inter-site variation compared with the intrasite variation. The fact that the samples from one area group together, separate from the samples from other sites, indicates that the variation in chemical signatures between different sites is greater than the variation in signature between samples from the one site. This is particularly notable for the Nilgiri samples. These samples come from
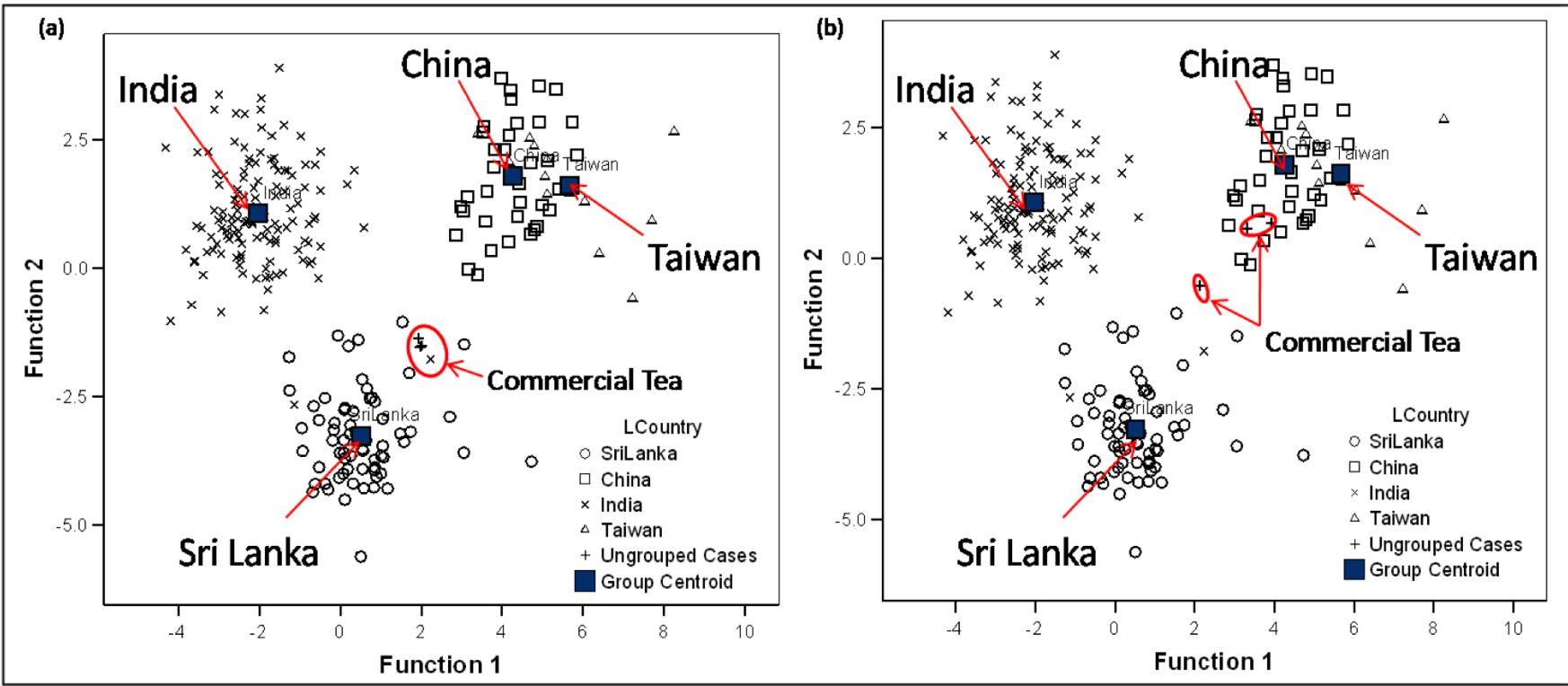

Fig. (10). (a) Example of classification that agreed with sample label. Discriminant plot indicating the grouping of commercial sample 3 (labelled Sri Lanka) compared with the Asian tea database. (b) Example of classification that disagreed with sample label. Discriminant plot indicating the grouping of commercial sample 5 (labelled India) compared with the Asian tea database.
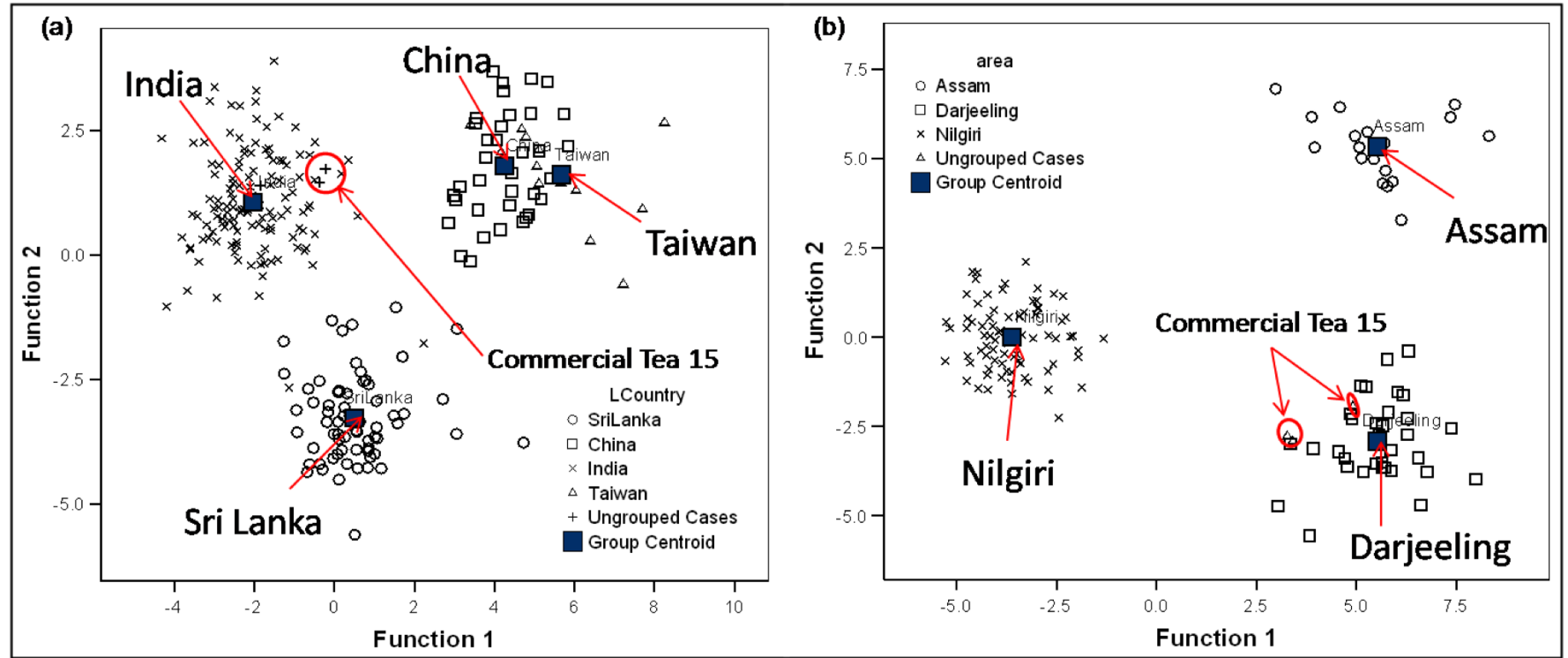

Fig. (11). Discriminant plot indicating the grouping of commercial sample 15 (labelled Darjeeling) compared with (a) the Asian tea database and (b) the Indian tea database. 
Table 2. Summary of Established Origin for Commercial Tea Samples Compared with the Origin Specified on the Label

\begin{tabular}{|c|c|c|c|c|c|c|c|}
\hline Sample \# & Type & Established Origin & Label & Sample \# & Type & Established Origin & Label \\
\hline \hline 1 & Jasmine & Taiwan & China & 12 & Black & India -> Darjeeling & Darjeeling \\
\hline 3 & Black & Sri Lanka & Sri Lanka & 15 & Black & India -> Darjeeling & Darjeeling \\
\hline 4 & Black & Sri Lanka & Sri Lanka & 16 & Black & Sri Lanka & Sri Lanka \\
\hline 5 & Black & 2 China/ 1 Sri Lanka & India & 17 & Black & India -> Assam & Assam \\
\hline 6 & Green & 1 China/ 2 Sri Lanka & India & 18 & Black & Sri Lanka & Sri Lanka \\
\hline 7 & Black & Sri Lanka & Sri Lanka & 19 & Black & Sri Lanka \\
\hline 8 & Black & China & China & 20 & Black & Sri Lanka & Sri Lanka \\
\hline 9 & Earl Grey & China & Unlabelled & 21 & Black & Sri Lanka & Sri Lanka \\
\hline 10 & Black & China & China & 22 & Black & Sri Lanka & Sri Lanka \\
\hline 11 & Black & China & China & 23 & Black & Blend \\
\hline
\end{tabular}

seven different plantations within Nilgiri. Samples also differed by grade, degree of processing, and harvest date (with a range of up to three years between harvests).

While it is obviously possible to distinguish between growing areas based on a chemical signature related to the local geology and climatology, it is also apparent from these data that the chemical signature of an individual area remains constant over a prolonged period of time. This is an extremely important aspect as it allows the investigator to establish a database for reference samples, specific to an individual area, without the requirement for an update annually. Because the signature is so stable over time there is an obvious implication that the geology and climatology are, to a large extent, responsible for the elemental distribution pattern in the tea and consequently it would be possible to develop a predictive database of teas based on these two parameters. If this is correct then it will be possible to predict the growing region of samples for which there is no data base entry, obviating the necessity of having data in a database to identify growing regions of suspect teas.

Thirty-two tea samples were collected for analysis from the Nilgiri (Blue Mountains) region of Southern India. After initially establishing that the Nilgiri teas could be separated from teas grown in other regions, using discriminant analysis (Fig. 8a), these samples were treated as a separate data set. The aim of this investigation was to establish whether samples could still be classified correctly despite seasonal and grade variations. In addition, the degree to which a sample could be distinguished from other samples grown in a similar area was also explored. Discriminant analysis was repeated exploring the separation that can be obtained comparing the signatures of the different plantations (Fig. 12a). $97.4 \%$ of cross-validated cases were correctly classified. The only samples that are not correctly classified are teas from the Havukal and Kairbetta gardens. The samples also appear to overlap. This is not surprising as the
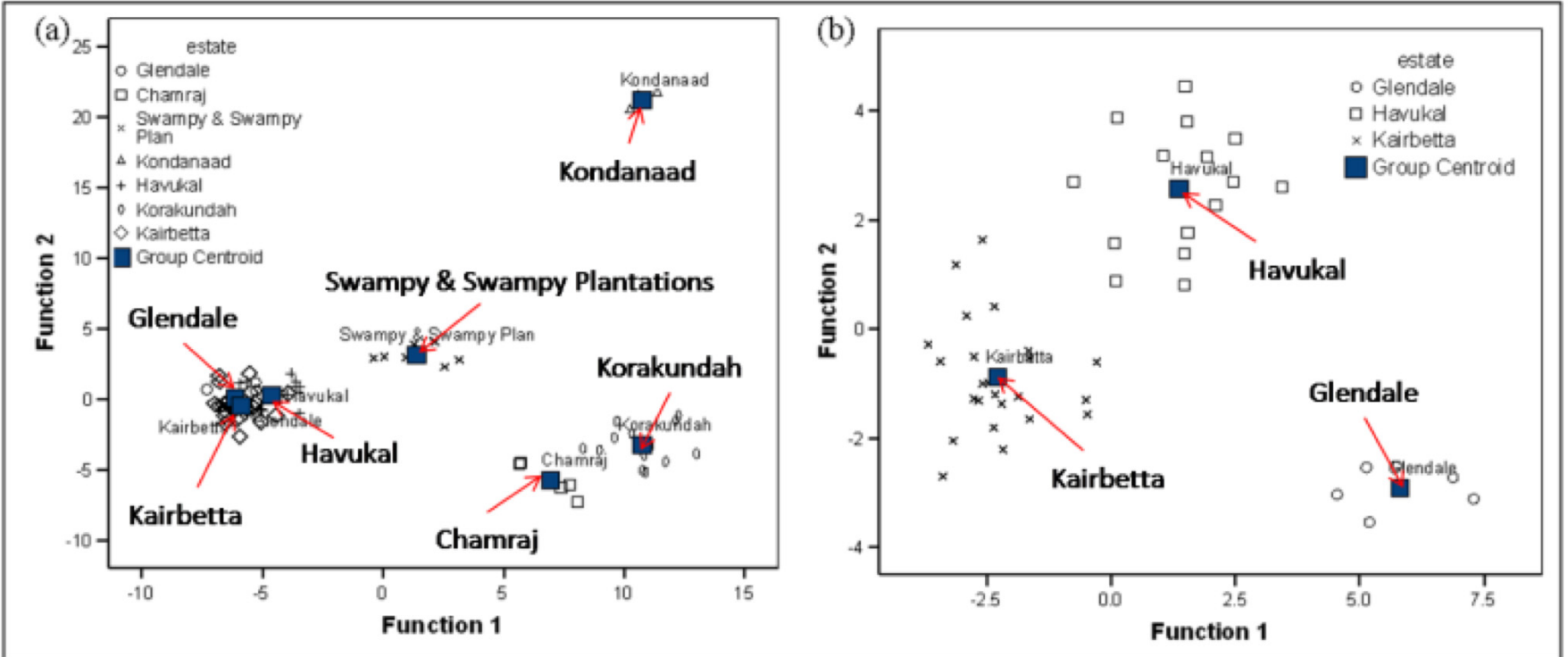

Fig. (12). (a) Scatter plot of the first 2 discriminant functions showing separation between tea samples from different tea gardens within the Nilgiri region of India. (b) Scatter plot of the first 2 discriminant functions of the reduced Indian tea dataset showing separation between Havukal, Kairbetta and Glendale tea gardens. 
Table 3. Coffee Samples Used Throughout this Study

\begin{tabular}{|c|c|c|c|c|c|c|}
\hline \multirow{2}{*}{$\begin{array}{c}\text { Name of Coffee: } \\
\text { Country and Plantation }\end{array}$} & \multirow{2}{*}{ Continent } & \multicolumn{2}{|c|}{ Label } & \multirow{2}{*}{$\begin{array}{c}\text { Name of Coffee: } \\
\text { Country and plantation }\end{array}$} & \multirow{2}{*}{ Continent } & \multirow{2}{*}{$\begin{array}{l}\text { Label } \\
\text { Green }\end{array}$} \\
\hline & & Roasted & Green & & & \\
\hline East Timorese & Oceania & 02EATIR & 02EATIG & Indian Tiger A & Asia & 17INTAG \\
\hline Kenyan & Africa & 03KENYR & 03KENYG & Australian Capricorn & Oceania & 18AUSCG \\
\hline Yellow Bourbon (Brazilian) & S. America & 05YEBOR & 05YEBOG & Papua New Guinean Elimbari & Oceania & 20PNGEG \\
\hline Ethiopian Harrar & Africa & 06ETHAR & 06ETHAG & Papua New Guinean PSC A & Oceania & 21PNGAG \\
\hline Ethiopian Yirgacheffe & Africa & 07ETYIR & 07ETYIG & Papua New Guinean Purosa A FTO & Oceania & 22PNGPG \\
\hline Kenyan AA & Africa & 08KEAAR & 08KEAAG & Cuban & N. America & 23CUBAG \\
\hline Ethiopian Harrar Gr 4 & Africa & - & 12ETHAG & Brazilian Delarisse & S. America & 27BRDEG \\
\hline Ethiopian Yirgacheffe & Africa & - & 13ETYIG & Colombian Supremo & S. America & $28 \mathrm{COSUG}$ \\
\hline Balinese Subak Abian & Asia & - & 14BASAG & Colombian Supremo Sc 18/19 & S. America & 29COSSG \\
\hline Indonesian Gajah Mountains & Asia & - & $15 \mathrm{INGMG}$ & Peruvian FTO & S. America & 30PERUG \\
\hline
\end{tabular}

gardens are adjacent to each other. However, if the samples from the estates that clearly separate from each other are removed and the discriminant plot redrawn it is then possible to identify all Nilgiri teas and place samples correctly into the specific production garden (Fig. 12b). This gives an indication of the discriminatory power of the technique.

\subsection{Coffee}

The coffee industry is one of the world's largest and is often the predominant source of income for many countries that rely on its trade for economic stability. Perhaps as a result of its status as an important global commodity, there exists a high risk of commercial coffee fraud. The ability to correctly identify coffee's geographic origin, or provenance, is important in establishing its authenticity. As a result, provenance establishment of coffee may assist in the prevention or detection of coffee fraud. One potential method of determining coffee provenance is the establishment of unique chemical signatures for coffee beans grown in different areas of the world. Although papers exist in the literature detailing the potential use of elemental concentrations to establish the provenance of coffee, the range of elements investigated is limited and there is no research associated with the potential use of ICP-MS as the analytical platform. The primary aim of this study was to develop a reliable and appropriate analytical method for establishing the provenance of coffee. A total of 39 green and roasted single origin coffee samples from 15 countries across five continents were obtained from a coffee retailer (Table 3). The analysis of the coffee samples was completed using a combination of solution ICP-MS and ICP-AES and LA-ICP-MS and isotope ratio mass spectrometry (IRMS).
In a previous study, Kelly et al. [10] have indicated that manganese is one of the most discriminating elements in establishing the provenance of coffee. In addition, various combinations of other elements including $\mathrm{K}, \mathrm{Ca}, \mathrm{Fe}, \mathrm{Ni}, \mathrm{Cu}$, $\mathrm{Rb}$ and $\mathrm{Sr}$ have also proven useful for differentiating coffees from various geographic origins. One major limitation of these previous studies is that they have been limited to elements present in relatively high concentrations and studies relating the trace elemental distribution pattern to the coffee's geographic origin are scarce. Statistical analysis of the data obtained from solution ICP-MS and ICP-AES analysis in the present study was performed in several steps in order to classify the coffee sample according to their geographic origin. After examining the elemental profiles, both linear discriminant analysis and principal component analysis were applied to the data in an attempt to achieve separation of the samples. As a preliminary investigation, the general trends across the elemental profiles for the coffee samples were compared in an attempt to discover whether there were any clear differences in elemental concentrations between the samples originating from different regions. With the exception of possibly $\mathrm{Na}, \mathrm{Sr}$ and $\mathrm{Ba}$, the elemental profiles of the coffees from the most varying regions (one each from four different continents) are not significantly different enough for direct comparison and discrimination. This suggests that there are only relatively slight differences in the inter-elemental associations between these coffees. This method of direct comparison of elemental profiles is insufficient to differentiate coffees from varying regions. For discrimination of the samples, more robust statistical methods are required. Linear discriminant analysis and principal component analysis were applied to the data for 
these purposes in the present study. With LDA providing the most promising results with respect to determination of country of origin of the study samples.

As a preliminary investigation, the total data set was examined in an attempt to separate the coffees according to their continent of origin: Africa, South America, North America, Asia and Oceania. When the data were plotted it appeared that samples from North and South America and Oceania were relatively clustered together (Fig. 13a). In order to determine if this was in fact correct and North and South American samples could not be separated, or simply a function of sample numbers and the software used, the data for these three areas were plotted separately. When this approach was undertaken, the three areas clearly separated (Fig. 13b), confirming that, using an iterative approach, it was possible to separate all coffee samples into their country of origin. Data for the green coffees (Table 3) were then subjected to the same statistical treatment, with equivalent separation being possible (Fig 14a, b). Cross validation also proved highly successful, with up to $92.2 \%$ correct classification of the samples.

Following this result, coffee samples from each continent were separated to test whether these pattern recognition techniques could classify them into their particular country of origin on the basis of elemental composition. The first set of data analyzed was from the African coffees and it is quite clear from the data plotted in Fig. (15) that separation is not only possible but extremely consistent and shows clear groupings related to the country of origin of the coffee samples. The maximum prediction rate obtained by cross validation was $92.1 \%$, indicating the reliability and validity of the model.
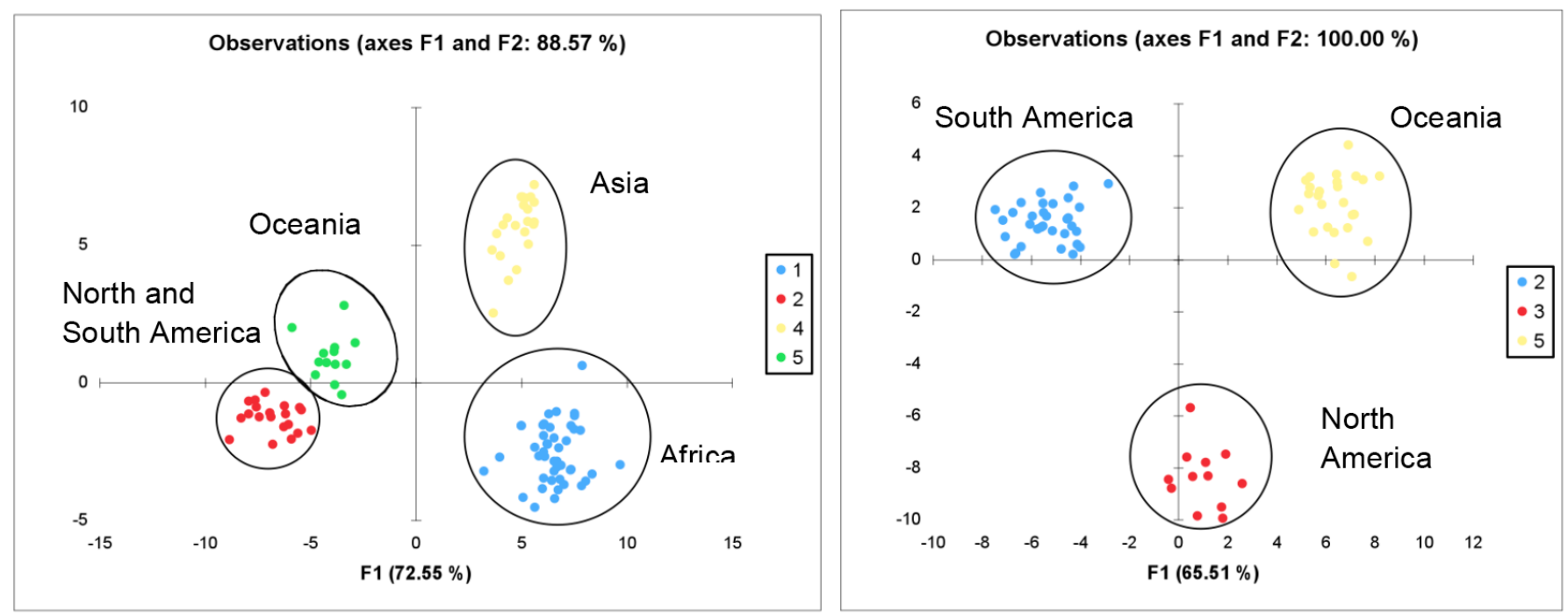

Fig. (13). (a) LDA plots showing the separation of coffees from Africa, South America, Asia and Oceania; (b) LDA plot showing the separation of coffees from South America, North America and Oceania based on all elemental concentrations obtained following acid digestion.
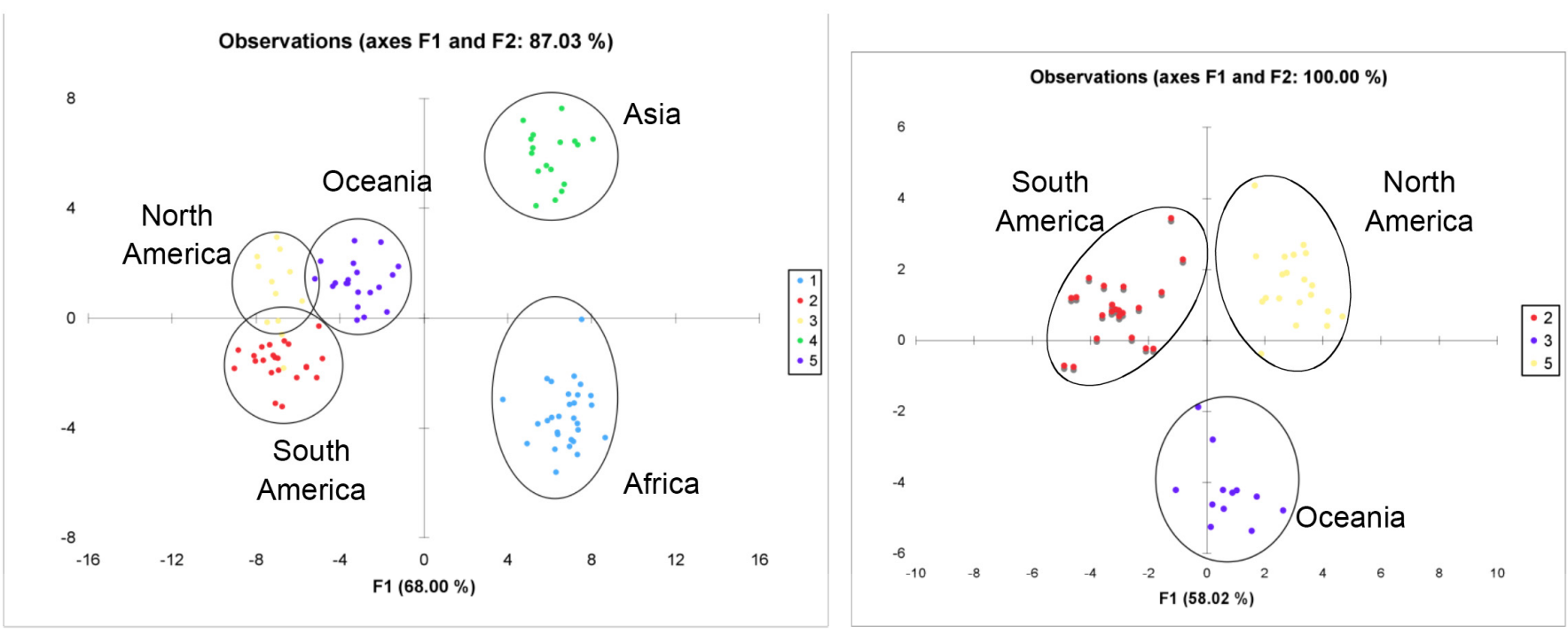

Fig. (14). (a) LDA plots showing the separation of green coffees from Africa, South America, North America, Asia and Oceania; (b) Additional separation of coffees from South America, North America and Oceania based on elemental concentrations obtained following acid digestion. 


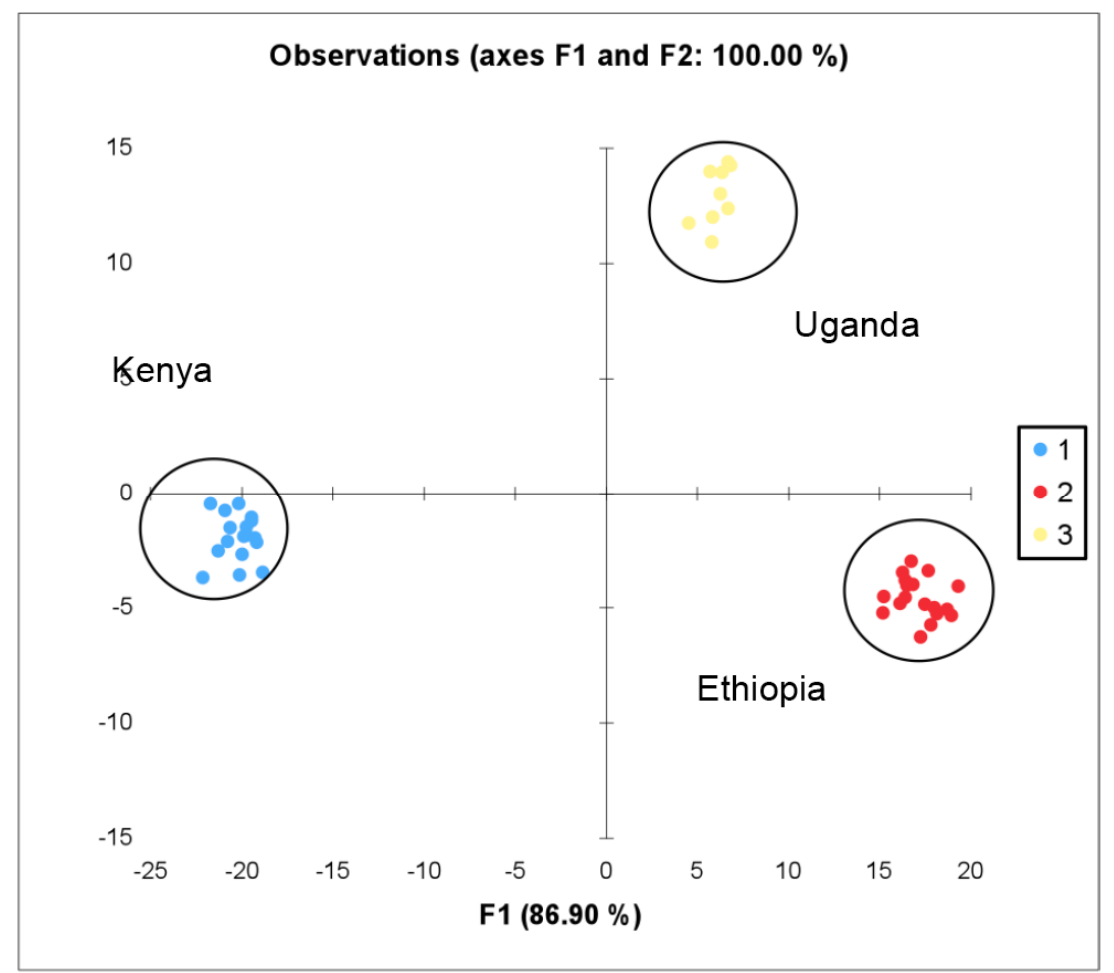

Fig. (15). LDA plot showing the separation of African coffees from Kenya (1), Ethiopia (2) and Uganda (3) based on elemental concentrations obtained from acid digestion.

The same separation is achievable for all other continents with, for example, South American coffees being able to be separated into Brazilian, Peruvian and Columbian sub groups and Asian coffees being able to be separated into Indonesian, Indian and Balinese with a high degree of precision (Fig. 16a, b). The accuracy of the LDA model was confirmed through the cross validation correct classification percentages of up to $96.0 \%$. Using only the elements $\mathrm{Sr}$, Mo, $\mathrm{Cs}, \mathrm{Ba}$ and $\mathrm{Ce}$ chosen through stepwise LDA. The number of North American coffee samples was quite small and although it was possible to separate all samples onto country of origin (Dominican Republic, Cuba, Guatemala) and, data are not plotted here. All other coffee samples could equally as convincingly be separated into country of origin.

\subsection{Olive Oil}

Traditionally, studies on the geographical origin of olive oil are based on organic properties such as the concentration of organic components [26-33] or stable isotope compositions [34-37]. However, the determination of trace elements in an oil based matrix is extremely difficult as, prior to analysis, it is necessary to completely oxidize the oil. This involves either the use of acids or some form of thermal oxidation procedure. These difficulties are compounded for olive oils as the levels of elements present are extremely low and the chance of significant contamination by dissolution chemicals is consequently extremely high. In addition, dilution of the sample may reduce the concentration of analytes to a level below the detection limit of the analytical technique, or introduce further trace impurities and mask any chemical profile of the sample. However, the ability to determine the trace element concentrations of olive oil samples has the potential to provide an extra level of discrimination in the determination of geographical origin. Until now determination of trace element composition of olive oils has not been possible, however, initial investigations using LA-ICP-MS have indicated that reliable trace element quantitation for an oil matrix is achievable and consequently the use of trace element signatures in olive oils to determine their provenance is, for the first time, a possibility. LA-ICP-MS was originally developed as a method for sampling solids while laser ablation of liquid samples has only been conducted in a limited number of studies [38-40]. It has been shown that it is possible to obtain a signal for a liquid sample using direct laser ablation. The future application of this technology for the analysis of similar foodstuffs that have oil type bases, for example, other types of consumable oils, butter and margarine, milk, cheeses and chocolate, all of which are difficult to dissolve using conventional oxidative acid digest, is obvious.

Thirty-two olive oil samples were collected from olive groves and retail outlets throughout Western Australia, the Mediterranean regions and USA. Samples $(40 \mu L)$ were dispensed by pipette into custom designed wells in a Perspex disc. Samples were ablated using optimized laser settings $(65 \mu \mathrm{m}$ spot, $5 \mathrm{~Hz}, 80 \%, 16.5 \mathrm{~J} / \mathrm{cm} 2)$. The laser was focused on the top of the sample. Samples and standards were spiked to $1 \mathrm{ppm}$ with lanthanum (5000 ppm Conostan ${ }^{\circledR}$ standard). This allowed for normalization of data obtained from the instrument. A 2 ppm Conostan ${ }^{\circledR}$ standard was analyzed every ten samples to monitor instrumental drift. The method of analyte additions was also used to provide a cross reference for quantitative data and to determine if there was any effect on analytical data by variations in the type of oil being analyzed. Analyte additions were undertaken by adding 


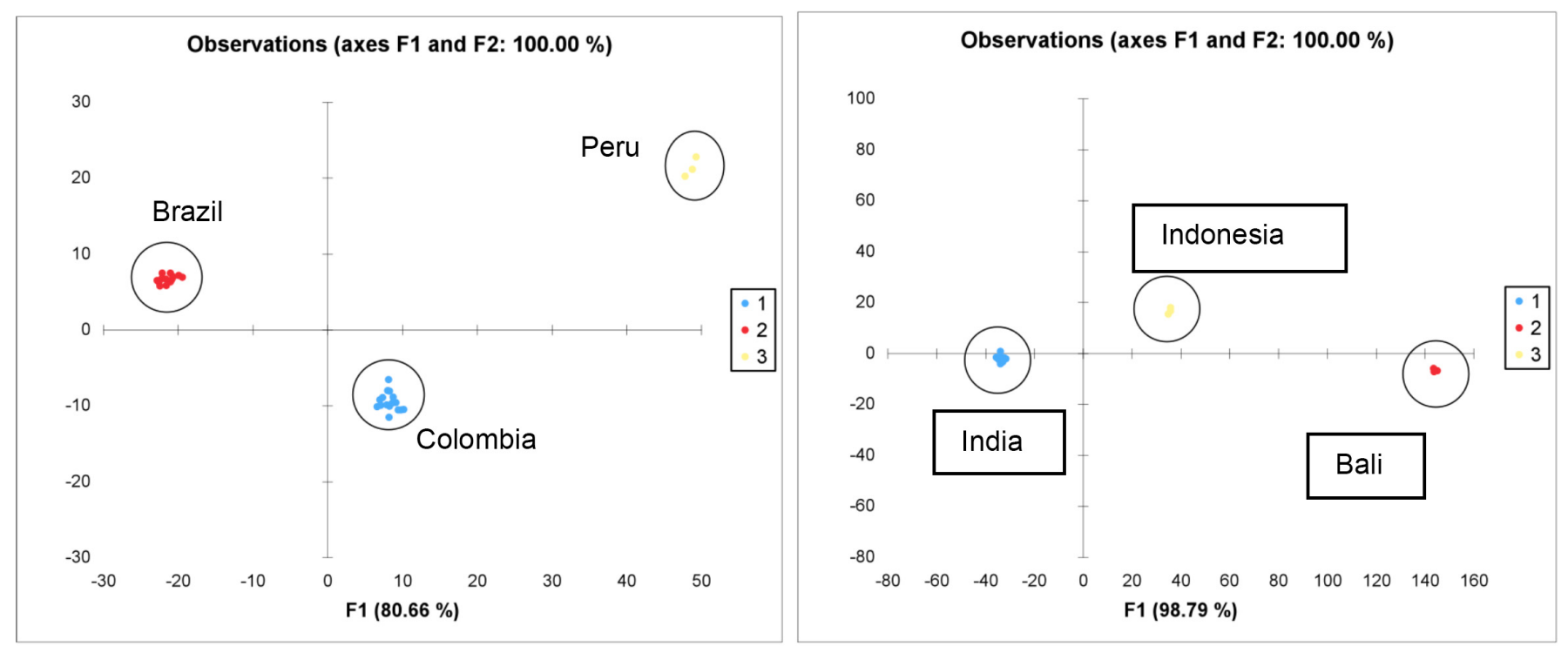

Fig. (16). (a) LDA plot showing the separation of South American coffees from Colombia, Brazil and Peru; (b) Asian samples being separated into Indian, Balinese and Indonesian based on elemental concentrations obtained from acid digestion.

known amounts of Conostan ${ }^{\circledR}$ multi element standard to a selection of olive oils samples.

Laser ablation is a sample introduction method that has been used in association with ICP-MS analysis for approximately 25 years [41]. The field has advanced significantly, especially in recent years, due to an increase in analytical sensitivity, reproducibility of laser coupling efficiency and reduction of sample size. This has resulted in a general increase in the applications to which combined LAICP-MS technology has been applied. In addition, the use of laser ablation reduces, and often completely removes, the amount of sample preparation required prior to analysis. Therefore samples can be analyzed directly thus avoiding any dilution or contamination of the analytes, which is extremely important when the concentrations of analytes are already very low, as is the case with olive oils.
The concentration range of the standards was determined by the expected levels of metals in the oil being analyzed. Olive oil has extremely low elemental concentrations, therefore it was important to analyze the lower concentration standards to establish if high precision and accuracy could be obtained for elemental concentrations in the appropriate range for the concentrations present in actual olive oil samples. Calibrations curves obtained for all elements had a correlation coefficient of greater than 0.94 with 19 of the 22 elements having a correlation coefficient greater than 0.996 and 12 of the 22 elements having a correlation coefficient greater than 0.999 . Standard addition was carried out on the olive oils as the blank base-oil Conostan ${ }^{\circledR}$ standard contained a higher concentration of many elements than the olive oil, therefore making the conventional external calibration method inappropriate. While in some instances, the correlation coefficient was lower than that obtained for the standards made up in the base oil, it was greater than 0.994

Table 4. Calculated Limit of Detection, Limit of Quantitation and \% Relative Standard Deviation

\begin{tabular}{|c|c|c|c|c|c|c|c|}
\hline Analyte & $3 \sigma$ LOD (ppb) & $\begin{array}{c}\text { 10б LOQ } \\
(\mathrm{ppb})\end{array}$ & \%RSD 1 ppm & Analyte & $3 \sigma$ LOD (ppb) & $\begin{array}{c}\text { 10б LOQ } \\
(\mathrm{ppb})\end{array}$ & \%RSD 1ppm \\
\hline${ }^{7} \mathrm{Li}$ & 0.9 & 2.9 & 3.23 & ${ }^{63} \mathrm{Cu}$ & 8.6 & 28 & 1.99 \\
\hline${ }^{11} \mathrm{~B}$ & 18 & 60 & 3.09 & ${ }^{66} \mathrm{Zn}$ & 7 & 23 & 4.78 \\
\hline${ }^{24} \mathrm{Mg}$ & 24 & 80 & 0.83 & ${ }^{88} \mathrm{Sr}$ & 0.1 & 0.5 & 1.02 \\
\hline${ }^{27} \mathrm{Al}$ & 40 & 134 & 2.35 & ${ }^{95} \mathrm{Mo}$ & 2 & 6.8 & 3.19 \\
\hline${ }^{49} \mathrm{Ti}$ & 12 & 40 & 3.01 & ${ }^{107} \mathrm{Ag}$ & 1.3 & 4.2 & 4.15 \\
\hline${ }^{51} \mathrm{~V}$ & 1.5 & 5.1 & 3.7 & ${ }^{111} \mathrm{Cd}$ & 3 & 10 & 3.82 \\
\hline${ }^{53} \mathrm{Cr}$ & 226 & 754 & 2.15 & ${ }^{115} \mathrm{In}$ & 0.2 & 0.6 & 2.85 \\
\hline${ }^{55} \mathrm{Mn}$ & 29 & 98 & 1.82 & ${ }^{120} \mathrm{Sn}$ & 5 & 16 & 3.55 \\
\hline${ }^{57} \mathrm{Fe}$ & 68 & 229 & 3.87 & ${ }^{121} \mathrm{Sb}$ & 2.3 & 7.7 & 4 \\
\hline${ }^{59} \mathrm{Co}$ & 0.5 & 1.7 & 1.14 & ${ }^{137} \mathrm{Ba}$ & 1.9 & 6.3 & 1.91 \\
\hline${ }^{60} \mathrm{Ni}$ & 1.9 & 6.3 & 2.47 & ${ }^{208} \mathrm{~Pb}$ & 1.2 & 4 & 2.6 \\
\hline
\end{tabular}


for all elements and greater than 0.999 for 13 of the 22 elements analyzed. Details of the detection limits achieved and limits of quantitation are given in Table 4.

With the extremely low detection limits obtainable using this technique, quantitative LA-ICP-MS analysis can now be applied to the direct analysis of olive oils and for that matter all other types of edible vegetable oils. Consequently, by using the data for at least 22 analytes, that can now be determined quantitatively using this technique, it will be far easier to provenance these and related, difficult to dissolve matrices, to their country of origin. A detailed paper on provenancing olive oils is now in preparation.

\section{CONCLUSIONS}

The multi-element, high sensitivity capability of ICPMS, ICP-AES and LA-ICP-MS has been used to obtain elemental signatures of a range of foodstuffs. Elemental analytical data, combined with light stable isotope ratio data, have facilitated the development of protocols that can be used to unambiguously source food and drink products back to their country of origin, and in some case back to their original plantation of growth. Protocols have also been developed for the quantitative elemental analysis of liquid samples, such as oils, using LA-ICP-MS. The use of this technology has meant that matrices, which are extremely difficult to breakdown using acid attack, from the point of view of their refractory nature, contamination by acids and loss of analytes by volatilization, can now have their element composition determined, even if, as is the case for olive oils, they are extremely low. Using multi-element signatures and isotope ratio profiles combined it has been possible to provide a far more robust and unambiguous provenance identification methodology than has been possible thus far. The protocols developed during the course of these investigations have also been positively used in both blind, independent trials and in actual test cases to validate the technology.

\section{ACKNOWLEDGEMENTS}

The authors would like to thank the Australian Wine and Brandy Corporation, especially Steve Guy and Jessica Pater for the supply of wine samples and Australian Pork Ltd, especially Darryl D'Souza and Bill Salter for help and coordination with pork processors in sample collection and the producers themselves for supplying samples for the study. We would also like to acknowledge Dean Gallagher and staff at 5 Senses Coffee in Rockingham, Western Australia for support and provision of all coffee samples, Hilary and Nigel White from Elmstock Tea, Perth Western Australia who provided many of the tea samples used and also to David Thompson from Larsen and Thompson, who provided a majority of the Indian tea samples.

The authors also wish to acknowledge technical support from Professor Kliti Grice and Sue Wang from Curtin University of Technology for technical assistance with IRMS and Hilary Stuart-Williams from the Australian National University for analysis of coffee samples for carbon and nitrogen stable isotope ratios, and the logistic and motivational support of Professor Ian Dadour of the Centre for Forensic Science of the University of Western Australia.
The authors also wish to acknowledge instrumental and financial support from TSW Analytical Pty Ltd. without which it would not have been possible to undertake the projects discussed in this paper.

\section{REFERENCES}

[1] Glennie, C. Chinese fraudsters ripping off NZ fruit, TV One News, June 27, 2004. http://tvnz.co.nz/view/video_popup_windows_skin 1432999 .

[2] Anonymous, Oz fruit a worry, Tasmanian Country, 27/06/2008, p. 4.

[3] ABC Online, Pork company defends use of imported ham, Retrieved from http://www.abc.net.au/rural/news/content/2007/s21 14318.htm, February 2008.

[4] Organization for Economic Co-operation and Development. the food and drink sectors, In: The Economic Impact of Counterfeiting and Piracy, Ch. 11, Rue André Pascal: Paris France, 2008, pp. 397.

[5] Herman, L. Determination of the animal origin of raw food by species-specific PCR. J. Dairy Res., 2001, 68, 429-436.

[6] Sacco, D.; Brescia; M.A.; Buccolieri, A.; Caputi, J.A. Geographical origin and breed discrimination of Apulian lamb meat samples by means of analytical and spectroscopic determinations. Meat Sci., 2005, 71, 542-548.

[7] Franke, B.M.; Gremaud, G.; Hadorn, R.; Kreuzer M. Geographic origin of meat-elements of an analytical approach to its authentication. Eur. Food Res. Technol., 2005, 221, 493-503.

[8] Heaton, K.; Kelly, S.D.; Hoogewerff, J.; Woolfe M. Verifying the geographical origin of beef: The application of multi-element isotope and trace element analysis. Food Chem., 2008, 107, 506515.

[9] Schmidt, O.; Quilter, J.M.; Bahar, B.; Moloney, A.P.; Scrimgeour, C.M.; Begley, I.S.; Monahan, F.J. Inferring the origin and dietary history of beef from $\mathrm{C}, \mathrm{N}$ and $\mathrm{S}$ stable isotope ratio analysis. Food Chem., 2005, 91, 545-549.

[10] Kelly, S.; Heaton, K.; Hoogewerff, J. Tracing the geographical origin of food: The application of multi-element and multi-isotope analysis. Trends Food Sci. Technol., 2005, 16, 555-567.

[11] Luykx, D.M.A.M.; van Ruth, S.M. An overview of analytical methods for determining the geographical origin of food products. Food Chem., 2008, 107, 897-911.

[12] Peres, B.; Barlet, N.; Loiseau, G.; Montet, D. Review of the current methods of analytical traceability allowing determination of the origin of foodstuffs. Food Control, 2007, 18, 228-235.

[13] Brereton, P. In: TRACE 1st annual meeting-Tracing the origin of food: York, United Kingdom, 2005.

[14] Perks, B. Fighting food fraud with science. Chem. World, 2007, 4, 48-52.

[15] Kabata-Pendias, A.; Pendias, H. Trace Elements in Soils and Plants, CRC Press Inc., Florida: 1984.

[16] Hernández-Jover, M.; Wu, M.; Schembri, N.; Holyoake, P.K.; Toribio, J-A.L.M.L. Technical note: evaluation of the official identification system for pigs for sale in New South Wales. J. Animal Sci., 2008, 86, 472-475.

[17] Valera, P.; Pablos, F.; Gonzalez, A.G. Classification of tea samples by their chemical composition using discriminant analysis. Talanta, 1996, 43, 415-419.

[18] Liu, X.; Van Espen, P.; Adams, F.; Yan, S.H.; Vanbelle, M. Classification of Chinese tea samples according to origin and quality by principal component techniques. Anal. Chim. Acta, 1987, 200, 421-430.

[19] Marcos, A.; Fisher, A.; Rea, G.; Hill, S.J. Preliminary study using trace element concentrations and a chemometrics approach to determine the geographical origin of tea. J. Anal. At. Spectrom., 1998, 13, 521-525.

[20] Moreda-Pineiro, A.; Fisher, A.; Hill, S. J. The classification of tea according to region of origin using pattern recognition techniques and trace metal data. J. Food Comp. Anal., 2003, 16, 195-211.

[21] Budinova, G.; Vlacil, D.; Mestek, O.; Volka, K. Application of infrared spectroscopy to the assessment of authenticity of tea. Talanta, 1998, 47, 255-260.

[22] Ferrara, L.; Montesano, D.; Senatore, A. The distribution of minerals and flavonoids in the tea plant (Camellia sinensis). Il Farmaco, 2001, 56, 397-401.

[23] Herrador, M. A.; Gonzalez, A.G. Pattern recognition procedures for differentiation of Green, Black and Oolong teas according to their 
metal content from inductively coupled plasma atomic emission spectrometry. Talanta, 2001, 53, 1249-1257.

[24] Matsuura, H.; Hokura, A.; Katsuki, F.; Itoh, A.; Haraguchi, H. Multielement determination and speciation of major-to-trace elements in black tea leaves by ICP-AES and ICP-MS with the aid of size exclusion chromatography. Anal. Sci., 2001, 17, 391-398.

[25] Pilgrim, T.S.; Watling, R.J.; Grice, K. Application of trace element and stable isotope signatures to determine the provenance of tea (Camellia sinensis) samples. Food Chem., 2008, 4, 921-926.

[26] Webster, L.; Simpson, P.; Shanks, A.M.; Moffat, C.F. The authentication of olive oil on the basis of hydrocarbon concentration and composition. Analyst, 2000, 125, 97-104.

[27] Lorenzo, I. M.; Pavon, J.L.P.; Laespada, M.E.F.; Pinto, C.G.; Cordero, B.M.; Henriques, L.R.; Peres, M.F.; Simoes, M.P., Lopes, P.S. Application of headspace-mass spectrometry for differentiating sources of olive oil. Anal. Bioanal. Chem., 2002, $374,1205-1211$.

[28] Bortolomeazzi, R.; Berno, P.; Pizzale, L.; Conte, L.S. Sesquiterpene, alkene, and alkane hydrocarbons in virgin olive oils of different varieties and geographical origins. J. Agric. Food Chem., 2001, 49, 3278-3283.

[29] Lazzez, A.; Perri, E.; Caravita, M.A., Khlif, M.; Cossentini, M. Influence of olive maturity stage and geographical origin on some minor components in virgin olive oil of the Chemlali variety. $J$. Agric. Food Chem., 2008, 56, 982-988.

[30] López-Feria, S.; Cárdenas, S.; García-Mesa, J.A.; Valcárcel, M. Classification of extra virgin olive oils according to the protected designation of origin, olive variety and geographical origin. Talanta, 2008, 75, 937-943.

[31] Salter, G. J.; Lazzari, M.; Giansante, L.; Goodacre, R.; Jones, A.; Surriechio, G.; Kell, D. B.; Bianchi, G. Determination of the geographical origin of Italian extra virgin olive oil using pyrolysis mass spectrometry and artificial neural networks. J. Anal. Appl. Pyrol., 1997, 40-41, 159-170.

[32] Dupuy, N.; Le Dreau, Y.; Ollivier, D.; Artaud, J.; Pinatel, C.; Kister, J. Origin of French virgin olive oil registered designation of origins predicted by chemometric analysis of synchronous excitation-emission fluorescence spectra. J. Agric. Food Chem., 2005, 53, 9361-9368.

[33] Tapp, H. S.; Defernez, M.; Kemsley, E. K. FTIR spectroscopy and multivariate analysis can distinguish the geographic origin of extra virgin olive oils. J. Agric. Food Chem., 2003, 51, 6100-6115.

[34] Angerosa, F.; Breas, O.; Contento, S.; Guillou, C.; Reniero, F.; Sada, E. Application of stable isotope ratio analysis to the characterization of the geographical origin of olive oils. J. Agric. Food Chem., 1999, 47, 1013-1017.

[35] Rezzi, S.; Axelson, D.E.; Heberger, K.; Reniero, F.; Mariani, C.; Guillou, C. Classification of olive oils using high throughput flow H-1 NMR fingerprinting with principal component analysis, linear discriminant analysis and probabilistic neural networks. Anal. Chim. Acta, 2005, 552, 13-24.

[36] Spangenberg, J.E.; Macko, S.A.; Hunziker, J. Characterization of olive oil by carbon isotope analysis of individual fatty acids: Implications for authentication. J. Agric. Food Chem., 1998, 46, 4179-4184.

[37] Spangenberg, J.E.; Ogrinc, N. Authentication of vegetable oils by bulk and molecular carbon isotope analyses with emphasis on olive oil and pumpkin seed oil. J. Agric. Food Chem., 2001, 49, 15341540.

[38] Bings, N.H. Direct determination of metals in lubricating oils by laser ablation coupled to inductively coupled plasma time-of-flight mass spectrometry. J. Anal. At. Spectrom., 2002, 17, 759-767.

[39] Günther, D.; Frischknecht, R.; Müschenborn, H.J.; Heinrich, C.A. Direct liquid ablation: a new calibration strategy for laser ablation ICP-MS microanalysis of solids and liquids. Fresenius' J. Anal. Chem., 1997, 359, 390-393.

[40] Günther, D.; Hattendorf, B.; Audetat, A. Multi-element analysis of melt and fluid inclusions with improved detection capabilities for $\mathrm{Ca}$ and $\mathrm{Fe}$ using laser ablation with a dynamic reaction cell ICPMS. J. Anal. At. Spectrom., 2001, 16, 1085-1090.

[41] Gray, A.L. Solid sample introduction by laser ablation for inductively coupled plasma source-mass spectrometry. Analyst, 1985, $110,551-556$

(C) Watling et al.; Licensee Bentham Open.

This is an open access article licensed under the terms of the Creative Commons Attribution Non-Commercial License (http://creativecommons.org/licenses/by$\mathrm{nc} / 3.0 /$ ) which permits unrestricted, non-commercial use, distribution and reproduction in any medium, provided the work is properly cited. 